\title{
WestVirginiaUniversity
}

THE RESEARCH REPOSITORY @ WVU

Graduate Theses, Dissertations, and Problem Reports

2016

\section{Attrition in parent-child interaction therapy}

Brittany K. Liebsack

Follow this and additional works at: https://researchrepository.wvu.edu/etd

\section{Recommended Citation}

Liebsack, Brittany K., "Attrition in parent-child interaction therapy" (2016). Graduate Theses, Dissertations, and Problem Reports. 6085.

https://researchrepository.wvu.edu/etd/6085

This Thesis is protected by copyright and/or related rights. It has been brought to you by the The Research Repository @ WVU with permission from the rights-holder(s). You are free to use this Thesis in any way that is permitted by the copyright and related rights legislation that applies to your use. For other uses you must obtain permission from the rights-holder(s) directly, unless additional rights are indicated by a Creative Commons license in the record and/ or on the work itself. This Thesis has been accepted for inclusion in WVU Graduate Theses, Dissertations, and Problem Reports collection by an authorized administrator of The Research Repository @ WVU. For more information, please contact researchrepository@mail.wvu.edu. 


\title{
Attrition in Parent-Child Interaction Therapy
}

\author{
Brittany K. Liebsack
}

\author{
Thesis submitted \\ To the Eberly College of Arts and Sciences \\ at West Virginia University \\ in partial fulfillment of the requirements for the degree of \\ Master of Science in \\ Psychology
}

\author{
Amy D. Herschell, Ph.D., Chair \\ Cheryl B. McNeil, Ph.D. \\ Amy L. Gentzler, Ph.D. \\ Department of Psychology
}

Morgantown, West Virginia

2016

Keywords: Attrition, Parent-Child Interaction Therapy, Hierarchical Linear Modeling, Predictors Copyright 2016 Brittany K. Liebsack 


\section{ABSTRACT \\ Attrition in Parent-Child Interaction Therapy}

Brittany K. Liebsack

Attrition is a significant problem in child psychotherapy (De Haan, Boon, De Jong, Hoeve, \& Vermeiren, 2013) and has serious implications. These include limited effectiveness of interventions for mental and behavioral health problems and decreases in staff productivity, access to services, and the number of people an agency can serve (Barrett et al., 2008). Predictors of attrition include those at the client, family, therapist, and treatment levels. The current study investigated the pattern of and variables associated with attrition in Parent-Child Interaction Therapy (PCIT), an evidence-based parent training program for families with young children (ages 2.5- to 7-years-old) with disruptive behavior disorders. Client- (i.e., child gender, child minority status, intensity of externalizing behavior); parent- (i.e., parent income, parent-to-child ratio, depression symptoms); and treatment-level (wait time for treatment, parent satisfaction with PCIT, therapist satisfaction with PCIT) variables; and competing activities and life stressors were examined. The sample of 134 parent-child dyads and 36 therapists recruited from 21 licensed psychiatric outpatient clinics across one state were part of a larger study (RO1 MH09750; A Statewide Trial to Compare Three Training Models for Implementing an EBT; PI: Herschell). The current study found an attrition rate of $73 \%$. Families were more likely to leave early in treatment, with 53\% of families leaving therapy after attending six or fewer sessions. Hierarchical Linear Modeling was used to examine predictors. Lower income, a smaller ratio of parents to children, longer wait time for PCIT, more reported life stressors and obstacles, and lower parent satisfaction with PCIT were all significantly associated with attrition. Qualitative data regarding additional therapist-reported reasons for attrition are reported. Limitations, suggestions for future research, and clinical implications are discussed. 


\section{Acknowledgments}

I would like to thank Dr. Amy Herschell for helping me develop a project that I am so excited about and interested in, and for allowing me to use data from her large grant, RO1 MH09750: A Statewide Trial to Compare Three Training Models for Implementing an EBT, for this project. I would also like to thank the other members of my committee, Dr. Cheryl McNeil and Dr. Amy Gentzler, for their valuable feedback during the development and implementation of this study. I am very grateful for all of the assistance, education, and support I received from the current and former members of the PCIT Across PA team at the University of Pittsburgh School of Medicine, especially Jon Hart and Shelley Heigel. Finally, I would like to thank my wonderful family and friends for their love, support, and encouragement. 
Table of Contents

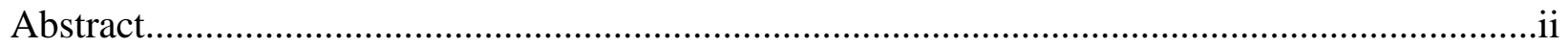

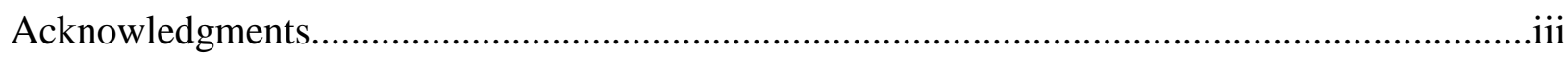

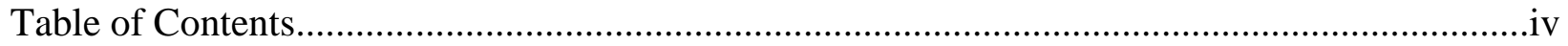

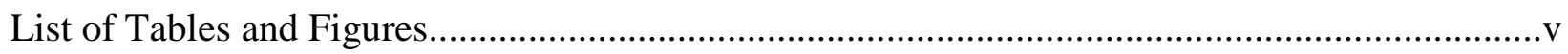

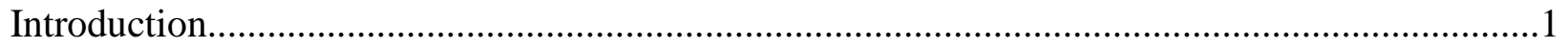

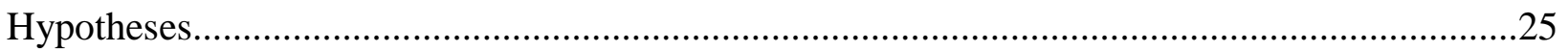

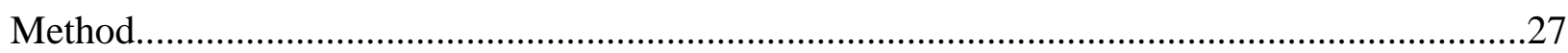

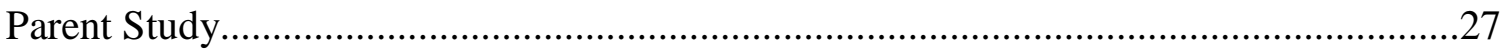

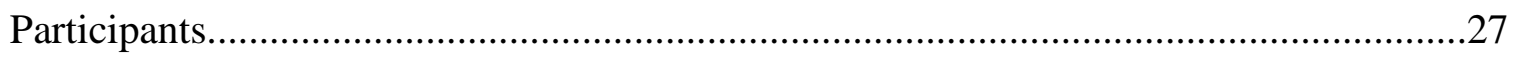

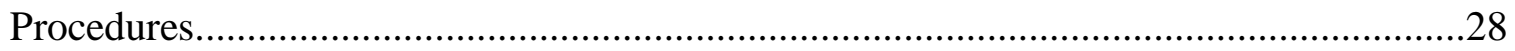

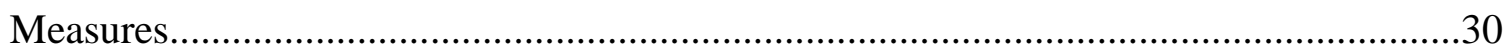

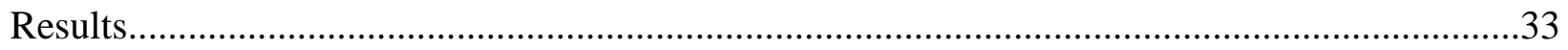

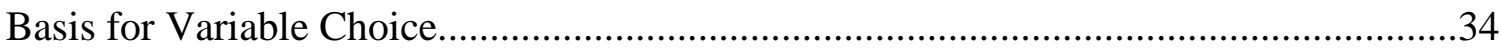

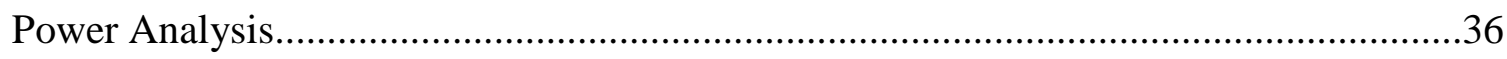

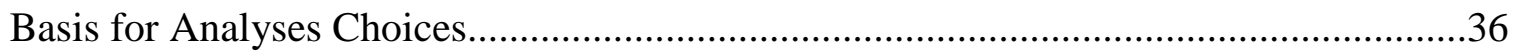

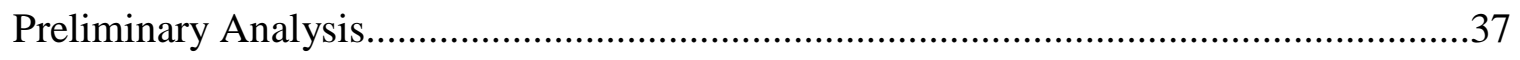

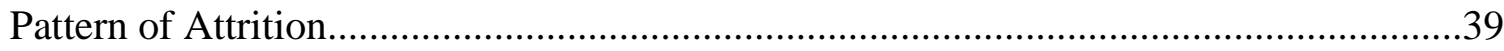

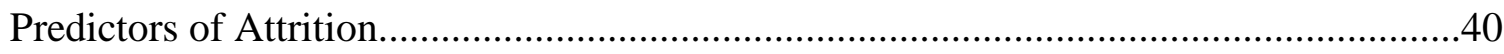

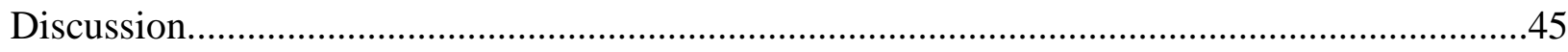

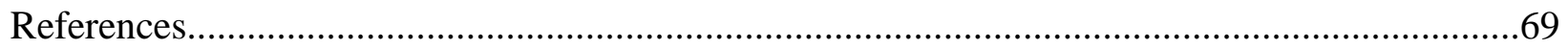

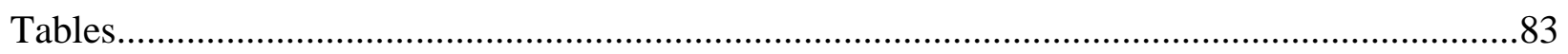

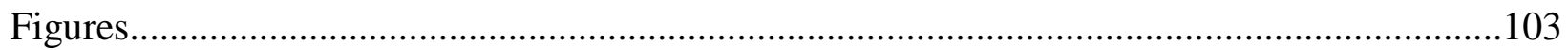




\section{List of Tables and Figures}

Table 1: Demographics for Children and Parents. .83

Table 2: Demographics for Children .84

Table 3: Demographics for Parents. .86

Table 4: Demographics for Therapists. .87

Table 5: Reasons for Variable Inclusion and Exclusion.......................................................89

Table 6: Means and Standard Deviations for Continuous Variables..........................................92

Table 7: Frequencies and Percentages for Categorical Variables.............................................93

Table 8: Intraclass Correlations Between Predictor Variables..................................................94

Table 9: Total CDI Sessions Attended by Families who Dropped Out.....................................95

Table 10: Number of PCIT Coach Sessions Attended..........................................................96

Table 11: HLM of Predictors of Attrition in PCIT...............................................................97

Table 12: Negative Impacts on Overall Course and Outcome of Treatment..............................98

Table 13: Other Negative Impacts on Overall Course and Outcome of Treatment......................99

Table 14: Reasons Why PCIT Services Ended................................................................100

Table 15: Other Reasons Why PCIT Services Ended.........................................................101

Table 16: Recommendations After Discharge.....................................................................102

Figure 1: Chart showing significant predictors of attrition in meta-analysis and PCIT studies..103

Figure 2: PCIT timeline for families who graduated........................................................104

Figure 3: Timeline of when families left therapy prematurely..............................................105

Figure 4: Total CDI coach sessions attended by families who dropped out.............................106 


\section{Introduction}

Attrition, or the act of leaving therapy prematurely, is a significant problem across various populations, settings, and treatment modalities and has important implications for clinical practice, service delivery, and research (Barrett et al., 2008). Based on Hatchett and Park’s (2003) conceptualization of attrition, premature terminators are defined as clients who discontinue therapy prior to recovering from the problems that led them to seek treatment (e.g., symptoms, functional impairment, distress). Attrition not only occurs in psychotherapy, it also occurs in behavioral medicine, exercise programs, physical therapy, and other types of treatment. Rates of attrition range from $10 \%$ to $59 \%$ in outpatient behavioral medicine treatments for stress, pain, headache and weight management (Davis \& Addis, 1999); from 7\% to 58\% in exercise programs (Linke, Gallo, \& Norman, 2011); and 20\% to 97\% in physical therapy (Wilder \& Barrett, 2005). In a meta-analysis of attrition in adult psychotherapy, Swift and Greenberg (2012) found an average attrition rate of $19.7 \%$. A meta-analysis conducted by De Haan, Boon, De Jong, Hoeve, and Vermeiren (2013) found an even higher percentage of attrition in child and adolescent therapies, with attrition rates ranging from $28 \%$ to $75 \%$.

Treatment attrition limits the effectiveness of interventions for mental and behavioral health problems (Barrett et al., 2008). This is a serious problem because untreated psychopathology often persists and worsens over time and can lead to negative outcomes. For example, children with untreated disorders are more likely than children who receive treatment to drop out of school, abuse alcohol and drugs, become unemployed, and engage in criminal behavior in adolescence and adulthood (Aebi, Plattner, Metzke, Bessler, \& Steinhausen, 2013;

Copeland, Shanahan, Costello, \& Angold, 2009). Additionally, unfilled appointments due to 
attrition decrease staff productivity, deny access to others waiting for services, and limit the number of people an agency can serve (Barrett et al., 2008).

Treatment attrition can be influenced and predicted by many variables including those at client-, therapist-, and treatment-levels, as well as therapy elements, attrition definition, and study design. In a meta-analysis of 669 studies representing 83,834 adult clients, results indicated that client age and diagnosis, setting for the intervention, provider experience level, definition of attrition used, and study design variables (e.g., efficacy or effectiveness study) all moderated overall attrition rate (Swift \& Greenberg, 2012). De Haan and colleagues (2013) found both study design and definition of attrition to be correlated with differences in attrition rates as well. Attrition percentages were higher in effectiveness than in efficacy studies. Results suggest that attrition definition was associated with attrition percentages in effectiveness studies. Additionally, pre-treatment child and family variables as well as therapist and treatment variables were predictors of attrition, with therapist and treatment variables being stronger predictors overall (De Haan et al., 2013).

The present study investigated child-, parent- and family-, and therapist- and treatmentlevel variables associated with attrition in one therapy, Parent-Child Interaction Therapy (PCIT) in community settings. PCIT is an evidence-based parent training program for families with young children (2.5- to 7-year-olds) with disruptive behavior disorders (DBDs). The purposes of the current study were to: (a) examine patterns of attrition in PCIT and determine when attrition from PCIT tends to occur most often and (b) determine what characteristics predict attrition. Next, the presented review defines attrition, details rates at which attrition occurs, and describes predictors of its occurrence. 


\section{Definition of Attrition}

Many terms are used to describe the problem of attrition (e.g., dropout, premature termination). “Attrition” will be used for the remainder of this paper, with participants being referred to as either “completers” or "premature terminators.” There are different ways to define attrition, including (a) failure to complete the treatment protocol (i.e., a full course of therapy), (b) failure to attend a predetermined number of sessions, or (c) failure to attend the last scheduled appointment without rescheduling or returning to any future sessions (Swift, Callahan, \& Levine, 2009). In addition, clients can be considered premature terminators if they discontinue therapy prior to evidencing a reliable improvement. Finally, attrition can be determined by the therapist or research team, who makes a judgment as to whether the client prematurely terminated after the client or participant has discontinued treatment. Some examples of reasons for therapists to consider a family an early terminator, according to Swift and colleagues (2009) are that the client stopped intervention without meeting therapeutic goals or gaining all available benefits, the client discontinued therapy before completing a "full course" of the intervention, or the therapist and client did not mutually agree that it was an appropriate time to end treatment. Attrition rates tend to be lower when attrition is defined according to therapist decision than when it is defined according to attendance at the last scheduled session or completion of a predetermined number of sessions (De Haan et al., 2013).

For the purposes of the current study, the first definition of attrition: failure to complete the treatment protocol (i.e., a full course of therapy) was used. Though there is no fixed number of sessions, the PCIT protocol uses a high standard of mastery criteria for each of the two phases of treatment (McNeil \& Hembree-Kigin, 2010). To successfully complete PCIT, parents must meet predetermined skill levels and their child’s behavior has to come within normal limits. 
Parent skills are measured by behavioral observation ratings (Dyadic Parent-Child Interaction Coding System, DPICS-III; Eyberg, Nelson, Duke, \& Boggs, 2005) and child behavior is measured by a standardized parent-report measure of intensity of behaviors and how problematic behaviors are (Eyberg Child Behavior Inventory, ECBI; Eyberg \& Pincus, 1999). The mastery criteria are widely used and valued; they are communicated in PCIT trainings, including the trainings attended by the therapists included in the current study, and used in most PCIT research studies. However, while allowing a parent to move forward in treatment or to graduate without meeting mastery criteria should be a rare exception, decisions are made on a case-by-case basis using clinical experience.

\section{Rates of Attrition in Child and Adolescent Therapies}

Child psychopathology is a significant public health issue that affects many children and families across the world (Merikangas, Nakamura, \& Kessler, 2009). In the United States, it is estimated that 13-20 percent of children experience a mental disorder each year (2009 National Research Council and Institute of Medicine report). While as many as one in five American children experience a mental disorder, it is estimated that as many as three-quarters of children who need mental health services do not receive care (Kataoka, Zhang, \& Wells, 2002). Of the children who do receive mental health care, a large proportion of cases result in attrition. In fact, in a meta-analytic review of treatment attrition in child and adolescent outpatient mental health care, De Haan and colleagues (2013) found attrition rates ranging from $28 \%$ to as high as $75 \%$.

\section{Importance of Treatment Retention}

These high rates of attrition are concerning because treatment completion is strongly related to therapeutic change (Kazdin \& Wassell, 1998), and untreated childhood disorders can have serious consequences. Childhood psychopathology, if left untreated, often persists or 
worsens later in life (Costello, Copeland, \& Angold, 2011). Children with untreated disorders are more likely to drop out of school, abuse drugs and alcohol, become unemployed, and engage in criminal behavior in adolescence and adulthood compared to children who receive treatment (Aebi et al., 2013).

Additionally, treatment attrition limits the number of people an agency can serve and increases the costs of providing clinical services. Because of decreased staff productivity, wasted treatment materials, and non-reimbursed appointments, per unit costs for services provided increases. Missed appointments occupy treatment slots that could be filled by others and unnecessarily increase the wait time for those on the waitlist (Barrett et al., 2008). Longer wait time allows psychological disorders to worsen, resulting in greater negative outcomes and disorders that are more difficult and take more time to treat (Barrett et al., 2008). Therefore, retention of children and families in treatment is imperative.

\section{Patterns of attrition.}

Researchers have examined patterns of attrition to better understand when in the course of treatment clients leave prematurely and what might predict or explain attrition. Attrition often occurs early in treatment (Kazdin \& Mazurick, 1994). In fact, in a meta-analysis of attrition in adults, $15.9 \%$ left therapy prematurely at pre-treatment, before attending even one therapy session (Fernandez, Salem, Swift, \& Ramtahal, 2015). In a sample of families with 6- to 12-yearold children receiving therapy, parents who perceived more barriers to treatment were more likely to terminate treatment after attending just one session (McCabe, 2002). In two studies of children with conduct problems, families who left therapy prematurely tended to do so after the assessment and during the early phase of treatment (Luk et al., 2001). Bados, Balaguer, \& Saldana (2007) found that 28\% of adults in psychotherapy left prematurely after the first session, 
and 52\% left treatment prior to the fifth session. In a review of attrition in adult therapy, Garfield (1994) found that the median length of stay in treatment is between five and six sessions and that more than $65 \%$ of adults end therapy before the tenth session. In a study of attrition for families with children referred for the treatment of oppositional, aggressive, and antisocial behavior, Kazdin and Mazurick (1994) looked at predictors of attrition separately in families who left therapy prematurely early on in treatment and families who left later in treatment. The authors considered early premature terminators to be families who had completed six or fewer weeks of treatment as the first six weeks were considered an initial stage where central features had yet to be implemented. Late terminators included families who had completed seven to 14 weeks of treatment. The researchers reasoned that, by this time in therapy, core features of treatment had already been implemented. Different predictors were found for early and late attrition (Kazdin \& Mazurick, 1994). Overall, the literature suggests that the majority of families attend six sessions of psychotherapy or less.

Early attrition might be due to a long wait time. Warnick, Gonzalez, Weersing, Scahill, and Woolston (2012) found that longer wait time predicted attrition in a study of 1098 families receiving services at an urban outpatient mental health clinic. When families have to wait to begin therapy, the crisis that brought them to treatment may be over, their child's behavior may be improving, and/or the parent may feel as though they have been waiting too long. This may be especially true for families with lower socioeconomic status (SES). Lorion (1974) described a “crisis-reactive” nature of poverty in which economically disadvantaged individuals attend to issues only after they have reached a critical level. Because these individuals are so burdened by major life needs, immediate and critical needs are prioritized and every effort is expended to get necessary services at that moment. However, when other crises emerge or when problem severity 
decreases and immediacy lessens, effort is redirected to more eminent problems (Lorion, 1974). Therefore, if families feel there is an immediate need, and they are not receiving services quickly enough, they may seek them elsewhere. Relatedly, the crisis may pass and the family may withdraw from treatment to attend to other needs that are perceived as more demanding.

Attrition may also occur early in treatment due to sudden gains or rapid response to treatment. The dose-effect literature suggests that most interventions require at least 11 to 21 sessions for $50 \%$ of clients to reach criteria for recovery (Lambert, 2007). However, the timing of treatment gains and treatment change varies from family to family. Researchers have examined sudden gains in treatment and rapid response, when in therapy they occur, and how much of the total improvement they account for. Sudden gains are large reductions in symptoms or large, maintained improvements from one session to another (Tang \& DeRubeis, 1999) and occur in many therapy cases. Tang and DeRubeis found that about $40 \%$ of adults in psychotherapy experienced sudden gains. They also found that more than $50 \%$ of the total improvements experienced during treatment were accounted for by these sudden gains (Tang \& DeRubeis, 1999). Ilardi and Craighead (1994) found that adults in therapy often experienced treatment gains at the beginning of treatment, which is called rapid response. Rapid response has also been found to account for a considerable amount of the total improvement in treatment. In a sample of adults with depression, depression symptoms decreased substantially by session four, at which point change leveled off. Of these early responders, about $41 \%$ achieved at least $60 \%$ of their total symptom reduction with the first five sessions alone (Hayes, Laurenceau, Feldman, Strauss, \& Cardaciotto, 2007). Rapid response has been found to occur in various diagnostic groups and treatment modalities (Haas, Hill, Lambert, \& Morrell, 2002; Stiles et al., 2003; Wilson, 1999), including PCIT, the treatment modality being examined in the current study. 
Hakman, Chaffin, Funderburk, and Silovsky (2009) found that patterns of parent-child interactions improved substantially during just three sessions of PCIT with child welfare involved parent-child dyads. In individuals or families who experience sudden gains or rapid response to treatment, families may experience reductions in symptoms and positive changes early in therapy, feel satisfied with their outcomes, and decide to leave therapy even if they have not completed the treatment protocol, completed a predetermined number of sessions, or completed a "full course" of treatment.

\section{Variables Related to Attrition}

The literature indicates that attrition is affected by client-, therapist- and treatment-level variables. For child treatments, client level variables include parent and family characteristics in addition to child characteristics. Parents often play an important role in attrition due to their active participation in their child's treatment and their responsibility for entering and completing treatment.

In a review of 48 peer-reviewed studies on attrition in child and adolescent therapies, De Haan and colleagues (2013) compared the study results on three major groups of attrition predictors: pre-treatment child factors, pre-treatment family or parent factors, and treatment and therapist variables or treatment participation barriers. All of the studies were done in outpatient settings and included participants between the ages of 0 and 20 years old. De Haan and colleagues differentiated between studies with efficacy and effectiveness designs and between studies with various definitions of attrition. These perspectives were combined to compare the study results, overall, in the different groups of attrition predictors. Effect sizes for the predictors were calculated (De Haan et al., 2013). See Figure 1 for an outline of the findings of the metaanalysis as well as five additional PCIT studies. The following is a review of De Haan and 
colleagues’ findings, including more detailed results from individual studies included in the meta-analysis. Additional studies examining predictors of attrition will also be discussed.

Child variables. De Haan and colleagues (2013) found that overall child characteristics significantly predicted treatment attrition. Of the 14 variables that were unique significant predictors of attrition, only one had medium to large effect sizes: More contact with deviant peers. The other effect sizes were small. However, of the predictors with small effect sizes, three were analyzed within at least ten studies with a large number of respondents: more externalizing problems reported by the parent or teacher, an externalizing disorder diagnosis, and ethnic minority status (De Haan et al., 2013). The remaining child variables with small effect sizes included: gender, with males more likely to become premature terminators; reasons for referral; lower IQ; poorer academic functioning; more externalizing problems as self-reported by the child; more parent-reported total problems; a diagnosis of an adjustment disorder; greater number of total diagnoses; and taking psychotropic medication (De Haan, 2013).

Child demographics. Client ethnicity was found to significantly predict attrition in a sample of 1098 families who received services at an urban outpatient mental health clinic (Warnick et al., 2012). That result was replicated in another community-based sample of over 400 children and adolescents, with African American youth attending fewer sessions than Caucasian youth (Miller, Southam-Gerow, \& Allin, 2008). Armbruster and Fallon (1994) studied 304 children and adolescents at a large, urban outpatient clinic for child mental health services, and their results also indicated that families with minority children were more likely to terminate prematurely. Minority status, however, was no longer a significant predictor when socioeconomic status (SES) was controlled for. However, Johnson, Mellor, and Brann (2009) found that neither minority group membership nor low socioeconomic status was associated with 
attrition, in a sample of 520 subjects. Older child age was found to predict lower parent expectancies for treatment but did not significantly predict attrition (Nock \& Kazdin, 2001). In summary, the following child demographic factors have been found to affect attrition: ethnic minority status, gender, IQ, and academic functioning (De Haan et al., 2013).

Child externalizing disorders. Childhood disruptive behavior problems, including persistent aggressive and/or oppositional behavior, are prevalent in the United States (Nock, Kazdin, Hiripi, \& Kessler, 2007) and are some of the most common reasons for referrals for child mental health services (Kazdin, 1995; Reid, 1993). While parent training has been found to be an effective "best practice” for externalizing behavior difficulties (Eyberg, Nelson, \& Boggs, 2008), families with children with more behavior problems are more likely to terminate treatment prematurely (Baruch, Vrouva, \& Fearon, 2009). Friars and Mellor (2007) investigated attrition in parenting programs for disruptive behavior disorders. The seven of the 18 clients (38.9\%) examined who terminated prematurely had children with more severe behavior problems and reported the perception that their child(ren) was more difficult than others. Similarly, in a sample of 405 2- to 15-year-olds referred for oppositional, aggressive, and antisocial behavior, severity of child dysfunction significantly predicted lower parent expectancies for treatment, which in turn predicted premature termination (Nock \& Kazdin, 2001). In summary, a diagnosis of an externalizing disorder is associated with a higher likelihood of prematurely terminating treatment. In families with children with behavior problems, the following factors have been found to affect attrition: more disturbed behavior and more severe dysfunction.

Other child problems/diagnoses. Low functioning per parent report (an evaluation of how well a child can maintain social relationships and complete daily activities) was found to 
predict attrition (Warnick et al., 2012). Additionally, in a study of 75 mothers referred to parent management training, parents who had been offered a clinical diagnosis for their children were more likely to terminate prematurely (Peters, Calam, \& Harrington, 2005). Youth with greater symptoms severity, with an adjustment disorder diagnoses, and/or with at least one Axis IV stressor were all more likely to become premature terminators (Miller et al., 2008). Lock, Courturier, Bryson, and Agras (2006) explored predictors of attrition in family therapy for families of adolescents with anorexia nervosa. Results suggest that youth with comorbid psychiatric disorders were more likely to terminate treatment prematurely (Lock et al., 2006). Dierke, Nargiso, Wiseman, and Hoff (2001) found that an overall risk for psychiatric problems, a greater number of depressed/isolated symptoms, more reasons for referral, and substance abuse all predicted attrition. Chasson, Vincent, and Harris (2008) found that depression, trauma-related symptom severity, increased avoidance behavior, and severity of intrusion all predicted attrition, as well. Contrary to the previous findings, however, Armbruster \& Fallon (1994) found that the premature terminators and completers in their sample were equally psychiatrically impaired. Similarly, in a comparison of 235 child and adolescent therapy premature terminators and completers in Hong Kong, families with children with a diagnosis of attention deficit hyperkinetic disorder or infantile autism were less likely to terminate treatment prematurely (Lai, Pang, Wong, Lum, \& Lo, 1998). In summary, the following child factors have been found to affect attrition: more severe and a greater number of symptoms/problems; more reasons for referral and referral source; risk for and diagnosis of psychiatric disorders, including an adjustment disorder diagnosis, having more comorbid disorders, and being on psychotropic medications; and lower social functioning. 
Parent variables. Results by De Haan and colleagues (2013) suggest that 13 pretreatment parent or family variables were significant overall predictors of attrition. Four parent or family characteristics had medium or large effect sizes. These included: younger mother age, homelessness, low parent confidence of doing well in treatment, and no mother knowledge of child diagnosis. The other nine variables had small but significant effect sizes. However, three of these variables had been tested in at least ten studies with a large number of participants: lower socioeconomic status (SES), more parent psychiatric problems, and single parent households without the father (De Haan et al., 2013). The other six predictors with small but significant effect sizes included: non-biological head of the household, poor parenting, greater number of children in the household, more parent internalizing and externalizing problems, and more negative life events reported by parent.

Parent and family demographics. In a study of 32 children at a community mental health center who presented with persistent conduct problems, Luk and colleagues (2001) found that mothers who were younger and less educated were more likely to terminate treatment prematurely. McCabe (2002) also found that less educated parents were more likely to terminate prematurely, in a study of Mexican-American families presenting for mental health treatment for a young child and a community mental health center. While several studies found lower socioeconomic status (SES or “money issues” to predict attrition (Armbruster \& Fallon, 1994; Garcia \& Weisz, 2002; Nock \& Kazdin, 2001; Peters et al., 2005), a couple have found that SES was not a significant predictor of attrition (Johnson et al., 2009; McCabe, 2002). Johnson and colleague’s (2009) results also showed that while families with more siblings living in the home may be more likely to terminate prematurely, single parenthood did not predict attrition. Alternatively, Warnick and colleagues (2012) found that residing in a single caregiver household 
did, in fact, predict attrition. Warnick and colleagues (2012) also found that children living with non-biological family were more likely to terminate therapy prematurely. Results also suggest that whether or not families were receiving state-funded, low-income insurance support also predicted attrition for some families (Warnick et al., 2012). Similarly, Armbruster and Fallon (1994) found that families who had insurance were more likely to continue therapy than those who were uninsured or had Medicaid. In summary, the following parent demographics have been found to affect attrition: younger mother age, more children in the home, and a non-biological head of the household. Additionally, while some studies found that families from a single-parent home and families with low socioeconomic status may be more likely to terminate prematurely, not all studies replicated these findings. Homelessness and a greater number of parent-reported life events have also been found to predict attrition (De Haan et al., 2013)

Parenting practices and expectancies. Friars and Mellor (2007) compared families who completed a behavioral management program for attention deficit hyperactivity disorder (ADHD) with premature terminators and found that parents who terminated prematurely perceived their children to be more difficult and reported experiencing more stress related to parenting. Completers reported a determination to persevere, especially when they credited an increased relationship with their child to strategies learned in therapy (Friars \& Mellor, 2007). Similarly, while parents who were highly critical of their child's behavior and made childresponsibility attributions were no more likely than non-blaming parents to prematurely terminate treatment, contrary to expectations, parents who expressed an understanding of their role in managing their child's behavior were more likely to continue therapy (Peters et al., 2005). In a study on family-based behavioral treatment for childhood obesity, parents who reported confidence in doing well in therapy pre-treatment were more likely to complete treatment. 
Additionally, confidence for doing well predicted child weight loss at the end of treatment (Gunnarsdottir, Njardvik, Olafsdottir, Craighead, \& Bjarnason, 2011). McCabe (2002) studied factors predicting attrition in Mexican-American families and found that parents who felt they should be able to overcome their child's emotional and behavioral problems on their own, using increased discipline, were more likely to terminate treatment prematurely. Additionally, mothers' knowledge of their child's diagnosis predicted attrition. In summary, the following pre-treatment parent factors have been found to predict attrition: parent self-efficacy, including the parent's determination to persevere through and confidence for doing well in treatment; parenting practices and beliefs about discipline; and parent knowledge and understanding the child’s problems and possible diagnosis.

Parent mental health. Nock and Kazdin (2001) also found that parental depression and greater parenting stress were both associated with lower expectancies for therapy which, in turn, predicted attrition. Depression also predicted attrition in Venable and Thompson's (1998) sample of 85 caretakers of children in counseling. However, caretakers who experienced self-criticism and delusional guilt were most likely to terminate prematurely. In a recent meta-analysis of adult therapy, attrition was significantly associated with diagnosis, with individuals with a diagnosis of depression having the highest attrition rate (Fernandez et al., 2015). Interestingly, anxiety did not seem to affect attrition (Venable \& Thompson, 1998). In a study of 520 child and adolescent mental health referrals, Johnson and colleagues (2009) found that parent psychopathology was associated with dropout for families diagnosed with family problems. In summary, parent psychopathology has been found to affect attrition.

Treatment and therapist variables. De Haan and colleagues (2013) found 26 treatment variables, therapist variables, or treatment participation barriers that were significant overall 
attrition predictors. The variables with medium to large or very large effect sizes were related to therapist alliance, parent perceptions of treatment, and factors related to scales of the Barriers to Treatment Participation Scale (BTPS; Kazdin, Holland, Crowley, \& Breton, 1997). The 18 variables with medium to very large effects included: more cancellations or no-shows, less positive parent rating of the therapist, an unbalanced therapeutic alliance between the child and each parent as well as with parents overall, a reduction in adolescent alliance as well as parent alliance. Dissatisfaction with the focus of therapy, low ratings of therapy organization, and high expectations that the child will recover quickly also had medium to large effects on attrition. Finally, the BTPS scales with medium or large effects included: total barriers, stressorsobstacles, and perceived relevance of treatment as rated by both the parent and the therapist as well as lower therapeutic relationship and more treatment demands according to the therapist. Variables with small effects but studied in at least 10 studies included: low parent rating of the therapeutic relationship and rating the therapist as more directive, controlling, and confronting. Finally, the variables with a small but significant effect included: no ethnic or gender match between the therapist and the child, more late arrivals by the family, lower child and parent alliance with the therapist, and more treatment demands on the BTPS according to the parent.

Therapist demographics. Lack of ethnic match between the child and the therapist was a significant predictor of Mexican-, African-, and Asian-American adolescent attrition after one session of therapy in a study of thousands of children and adolescents in the Los Angeles County Mental Health System (Yeh, Eastman, \& Cheung, 1994). However, when language match was added to the model for Mexican-American adolescents, it significantly predicted attrition while ethnic match was no longer a significant predictor. In another study of Mexican-American families who presented for mental health treatment for a young child at a community mental 
health center, client-therapist ethnic match was also a predictor of attrition. Armbruster and Fallon (1994) found that racial or ethnic match between parent and therapist only predicted attrition when a minority therapist was assigned a nonminority parent. Lack of gender match between the child and therapist was also found to predict attrition (De Haan et al., 2013).

Therapeutic alliance. The quality of the therapist-family relationship is one barrier to treatment that has been well studied and consistently found to be an important predictor of attrition. Garcia and Weisz (2002) found, in a comparison of parents of 344 youth who had either completed or terminated outpatient treatment prematurely, that therapeutic relationship problems accounted for most of the variance that distinguished premature terminators from completers. In 147 families in family treatment with a markedly aggressive child, families who terminated prematurely reported greater dissatisfaction with the therapist (Prinz \& Miller, 1994). Pereira, Lock, and Oggins (2006) examined the role of therapeutic alliance on attrition in family therapy for adolescent anorexia nervosa. They found that a strong early alliance with parents prevented attrition after 12 months. In a sample of families in multidimensional family therapy for adolescents who abuse drugs, both adolescent alliance with the therapist and mother-therapist alliance, measured at the second therapy session, discriminated between completer families and premature terminators (Robbins et al., 2006). In a sample of 225 children and adolescents from four community mental health centers, quality of the therapist-family relationship was consistently related to premature dropout (Stevens, Kelleher, Ward-Estes, \& Hayes, 2006). While Robbins, Turner, Alexander, and Perez (2003) found that individual parent and adolescent alliances with the therapist did not predict attrition in their sample of 34 families, they did find that premature terminators had significantly higher unbalanced alliances (parent minus adolescent) than completers. This finding was replicated in a study of Hispanic- and Anglo- 
American families of adolescents who abused substances and were participating in functional family therapy. Flicker, Turner, Waldron, Brody, and Ozechowski (2008) also found that Hispanic families who terminated treatment prematurely had a greater imbalance in alliance (parent-adolescent) than those who terminated prematurely. Interestingly, this was not true for Anglo families (Flicker et al., 2008). In a study of 65 youth and their parents, Hawley and Wiesz (2005) found that greater therapist agreement with the family’s decision to terminate therapy was significantly related to therapist-parent alliance but was not related to therapist-youth alliance. Parent alliance was also related to more frequent family participation and less frequent no-shows and cancellations. (Hawley \& Weisz, 2005). To summarize, parent and child/adolescent satisfaction and/or relationship with the therapist as well as balanced therapeutic alliances between the parent and child have been found to affect attrition.

Parent barriers to treatment participation. Other barriers to treatment, in addition to therapeutic alliance, have also been found to predict attrition. De Haan and colleagues (2013) found that pre-treatment child variables, pre-treatment family characteristics, and treatment and therapist variables were all strong overall attrition predictors. However, therapist and treatment variables predicted attrition more strongly than child or family variables. Some studies analyzed whether BTPS barriers moderated risk of attrition and a moderating effect was found. Results suggest that perceived barriers can increase the risk of attrition while not experiencing barriers can reduce the risk for terminating prematurely, even with families who were at high risk according to the presence of certain pre-treatment predictor variables. Some barriers to treatment participation found to affect attrition include lower perceived relevance of treatment, treatment rated as more demanding by therapist, and more parent- and therapist-reported stressorsobstacles (De Haan et al., 2013). 
In a study of 147 families with an aggressive child, dropouts were clearly distinguishable from completers (Prinz \& Miller, 1994). In general, premature terminators reported a greater number of situational problems than did completers. Eighty-six percent of the reasons for attrition given by the premature terminators were situational reasons or environmental or logistical obstacles caused by their current life situation. In a sample of Mexican-American families with young children, parents who perceived more barriers to treatment were more likely to terminate treatment after attending just one session (McCabe, 2002). Additionally, parents who expected their child to recover quickly were more likely to terminate after just one session. In 405 children referred for oppositional, aggressive, and antisocial behavior, Nock and Kazdin (2001), found that pre-treatment parental expectancies for their child's psychotherapy predicted premature termination from therapy.

In a study of 18 parents of adolescents with ADHD, ODD, CD, or a combination referred to behavioral management group programs, results suggested that parents who terminated treatment prematurely did not believe that the strategies proposed in the program to help their child were useful (Friars \& Mellor, 2007). Similarly, in a study of 225 child and adolescents from four community mental health centers serving diverse families, attrition was related to the perceived relevance of treatment (Stevens, Kelleher, Ward-Estes, \& Hayes, 2006). Johnson and colleagues (2009) found that factors associated with attrition varied across disorders. For children and adolescents with conduct disorder, treatment modality was the only factor studied that significantly predicted attrition. Treatment length was associated with higher rates of attrition in a sample of adolescents with anorexia nervosa in family therapy, with those randomly assigned to longer treatment being more likely to prematurely terminate therapy (Lock et al., 2006). This could potentially be due to dissatisfaction with the length of treatment. To 
summarize, treatment modality, treatment length, parental perceived relevance and usefulness of treatment, and unrealistic parent expectations about child recovery have been found to affect attrition.

Parent satisfaction with treatment. While treatment satisfaction was not examined in the De Haan meta-analysis (2013), specifically, two studies included in the meta-analysis did examine treatment satisfaction as a predictor of attrition. In 147 families in family treatment with a markedly aggressive child, families who terminated prematurely reported greater dissatisfaction with the intervention (Prinz \& Miller, 1994). Luk and colleagues (2001) also found that parents who terminated prematurely were more likely to be dissatisfied with treatment services and to perceive that the treatment was less organized.

\section{Conceptual Model of Attrition}

Kazdin and colleagues (1997) found that some family, parent, and child characteristics predicted attrition. They also found that perceived barriers to treatment also contributed significantly to attrition and could not be explained by the client characteristics. Among the families at high risk for terminating treatment prematurely, based on family, parent, and child characteristics, the perception of few barriers reduced risk. These results informed the development of a conceptual model called the barriers-to-treatment model (Kazdin et al., 1997).

According to the model, variables such as parent perceptions about treatment (e.g., treatment is demanding, is not helpful, and is not relevant to the child's problems), therapeutic alliance, and practical obstacles related to participation such as transportation both hinder participation to treatment and contribute to attrition. Furthermore, parent or family variables, such as low SES, may influence perceptions of barriers, which then predict attrition (Nock \& 
Kazdin, 2001). Research shows perceptions of barriers may even contribute to attrition over and above the contribution of more well-studied family, parent, and child factors.

Barriers to treatment and predictors of attrition, however, vary across different cultures and ethnicities (Lai et al., 1998; Yeh et al., 1994), different diagnoses (Johnson et al., 2009; Miller et al., 2008), different treatments (Lock et al., 2006; Luk et al., 2001; Prinz \& Miller, 1994), and even different phases of treatment (Armbruster \& Fallon, 1994). This study will examine the specific predictors of attrition in one evidence-based treatment, Parent-Child Interaction Therapy (PCIT).

\section{Parent-Child Interaction Therapy}

Parent-Child Interaction Therapy (PCIT; Eyberg \& Funderburk, 2011; McNeil \& Hembree-Kigin, 2010) is an empirically-supported, manualized parent training intervention for 2.5- to 7-year-olds with disruptive behavior as well as families who have experienced or are at risk for experiencing physical abuse. PCIT is designed to improve parent-child relationships and to reduce a range of externalizing behavior problems including oppositional behaviors, aggression, noncompliance, and tantrums. In PCIT, parents are taught specific skills to improve the quality of the parent-child relationship while helping to increase their child's positive behavior and decrease negative behavior. PCIT is designed to be an office-based intervention. The therapist observes the parent-child interaction from behind a two-way mirror and communicates with and coaches the parent in his/her interactions using an ear piece. The two phases of PCIT include Child-Directed Interaction (CDI) and Parent-Directed Interaction (PDI). In CDI, the main goal is to strengthen the parent-child relationship. The therapist coaches parents in the use of play therapy skills designed to increase positive parent behaviors and support social interaction. The PDI phase builds on the foundation of CDI skills. In this phase, skills including 
the use of limit-setting, commands, and consequences (e.g., timeout) are introduced to decrease disruptive behavior and noncompliance. These skills are designed to further strengthen the parent-child relationship and reduce negative child behaviors and harsh discipline tactics.

There is no fixed number of sessions for each phase; the two phases are delivered consecutively with progress to PDI contingent on CDI skill mastery. Completion of the entire PCIT program and graduation is contingent on mastery of PDI skills. Skills are assessed for five minutes at the beginning of each session. CDI mastery criteria include the parent using at least ten each of three positive verbalizations: labeled praises, behavior descriptions, and reflections, with 3 or fewer commands, questions, and criticisms. While moving on to PDI should be contingent upon mastery of CDI, therapists must sometimes use their judgment to decide whether moving forward without one or both parents meeting mastery is in the best interest of the child. This might occur if the caregiver has had 10 or more CDI coaching sessions and has still not reached mastery, if he/she is missing mastery by only a couple of skills, or if the family is at risk of dropping out of treatment because due to frustration related to not moving forward in treatment (McNeil \& Hembree-Kigin, 2010). These decisions are made on a case-by-case basis using clinical experience. Specific mastery criteria have also been established for the PDI phase of PCIT. They include: (a) the parent providing at least four commands, with $75 \%$ of the commands being “effective” and (b) using 75\% correct follow-throw, (c) successful use of the time-out procedure, and (d) parent-report of child behavior problems in the normal range. The average length of treatment is between 12 and 14 weeks, with CDI typically lasting four weeks and PDI lasting six weeks (McNeil \& Hembree-Kigin, 2010).

\section{Attrition in Parent-Child Interaction Therapy}


Attrition among families receiving PCIT, like most behavioral health interventions, is an ongoing challenge. Predictors of attrition in PCIT have been identified at parent-, family-, and therapist-levels and rates of attrition range from $50 \%$ to $69 \%$ in previous studies. In an efficacy study of 50 families participating in PCIT, Werba, Eyberg, Boggs, and Algina (2006) explored pre-treatment predictors of attrition by comparing 33 treatment completers with 17 premature terminators on demographic characteristics (e.g., SES), child characteristics (e.g., severity of disruptive behavior), maternal characteristics (e.g., maternal IQ), and parental behavior management skills (e.g., observed caregiver prosocial behavior toward child). To be identified as a treatment completer, mothers were required to meet highly specific treatment completion criteria. The criteria included: (a) mothers demonstrating criterion levels of the interaction skills taught during treatment, (b) mothers reporting that the child's three primary presenting problems had been resolved, (c) mothers reporting fewer than five ODD symptoms for her child, and (d) children demonstrating at least 75\% compliance to parent commands. In a multiple regression analysis, only maternal distress (a variable created by combining maternal depression and stress scores) and negative maternal verbal behavior directed to the child (critical and sarcastic comments) were found to predict treatment attrition. In a long-term follow-up study of 46 (92\%) of the families one to three years later, premature terminators were asked why they left therapy. Primary reasons included: logistical problems (being unable to find child-care or transportation; 35\%); feeling unable to wait for treatment or feeling that treatment was progressing too slowly (19\%); and dissatisfaction with the treatment approach or techniques (16\%; Boggs et al., 2004). In an effectiveness study of 120 parent-child dyads comparing in-home to standard office-based PCIT, only 37 (31\%) of families completed treatment (Lanier, Kohl, Benz, Swinger, \& Drake, 2011). Completion of PCIT was contingent upon mastery of PDI skills. According to 
Lanier and colleagues (2011), while there was no difference found in attrition between referral source or treatment setting, attrition was predicted by parent income and therapist rating of parent occupational and psychosocial functioning; with treatment completers having higher incomes and higher ratings of functioning. In a pilot study of engagement in and effectiveness of PCIT services delivered to low SES, ethnic minority children and their parents in an urban setting, four of the 12 families (33\%) completed treatment (Lyon \& Budd, 2010). In this study, attrition was defined as occurring either when a caregiver told the therapist that he/she wanted to end treatment or just stopped coming to all scheduled parent training sessions. Completers were more likely to be self-referred, demonstrated fewer cancellations and higher levels of attendance, and reported experiencing fewer barriers. They also seemed to report higher levels of satisfaction with therapy than premature terminators, though this effect did not reach significance.

In an efficacy study of 22 families with 3- to 6-year-old children diagnosed with ODD, Harwood and Eyberg (2004) focused on therapy process variables in PCIT rather than parent, child, and family characteristics. The study considered the effect of early therapist behaviors in interactions with parents as predictors of treatment completion. Treatment completion occurred when graduation criteria were achieved. Graduation criteria included parent ratings of child behavior within normal limits and mastery of the PCIT skills. Findings suggest that successful completion of PCIT can be predicted by a good parent-therapist relationship early in treatment. Results also showed a significant difference in SES between completers and premature terminators, with premature terminators having a lower average SES.

In summary, previous research has found that the following variables affect attrition in PCIT: low SES, poorer therapist rating of parent psychosocial and occupational functioning, more parent cancellations and no-shows, more parent-reported barriers to treatment participation, 
and therapist verbalizations/therapy style. Additionally, families who were self-referred were less likely to terminate PCIT prematurely while parents who felt that treatment was not progressing quickly enough, who had to wait longer for treatment to begin, and who were less satisfied with therapy were more likely to terminate prematurely.

\section{Purpose of the Present Study}

The current study attempted to replicate findings from the recent meta-analysis of attrition in child and adolescent therapies (De Haan et al., 2013) as well as the five previous studies that have examined attrition in PCIT, specifically. Previous studies on attrition in PCIT have largely focused on parent and family characteristics, such as low SES and maternal characteristics. These variables are static and cannot be changed throughout the course of treatment. However, the literature on other child outpatient treatments indicates that many barriers to treatment participation, therapist characteristics, and therapy process variables, such as parent and therapist satisfaction with treatment and practical obstacles related to participation play a significant role in treatment attrition. These may affect attrition in PCIT even more than the contribution of family, parent, and child factors which are studied more frequently (Kazdin et al., 1997) and should be examined.

The current study used failure to complete the treatment protocol, or to meet PDI mastery criteria and graduate from treatment, to define PCIT completion or attrition. The current study examined whether child-, parent- and family-, and therapist- and treatment-level variables that have been found to predict attrition in various other child and adolescent treatments also predict attrition in PCIT. Additionally, this study built on the existing literature by examining therapist characteristics and therapy process variables that have not yet been examined in previous studies of attrition in PCIT. It will also be the largest study of attrition in PCIT, to date. Last of all, the 
current study offers a new contribution by examining whether or not a specific pattern of attrition exists in PCIT.

\section{Hypotheses}

\section{Exploratory Question 1}

Are there specific patterns of attrition, with more families terminating early in treatment than later in treatment? Do families terminate at specific times in PCIT (e.g., after CDI teach, during CDI, after PDI teach, or during PDI)?

It was hypothesized that the highest attrition rates for PCIT, by session, would occur early in treatment. It was hypothesized that there would be a high attrition rate after the CDI teach session, especially because families had gone through the agency intake, the PCIT intake, and the CDI teach sessions; had been attending sessions for almost a month and had not yet received treatment. Because of this, the crisis that brought them to treatment may have been over, their child's behavior may have been improving, and/or the parent may have felt as though they had been waiting too long. This may be especially true for lower SES families because of the “crisis-reactive” nature of poverty (model by Lorion, 1974). This model suggests that, because economically disadvantaged individuals are so burdened by major life needs, only critical issues receive attention.

\section{Exploratory Question 2}

Do certain child characteristics that have been found to correlate with attrition in previous studies significantly predict attrition in PCIT as well? Are boys, ethnic minority children, and children with externalizing behavior problems more likely to be early terminators? 
It was hypothesized that male gender, minority status, and a higher level of externalizing problems as represented by higher scores on the Eyberg Child Behavior Inventory (ECBI; Eyberg \& Pincus, 1999) would predict attrition.

\section{Exploratory Question 3}

Are pre-treatment family or parent characteristics associated with attrition? Do certain parent and family demographics such as family income and ratio of parents to children in the home predict attrition? Is parental depression associated with attrition?

It was hypothesized that parents who were poorer, had fewer caregivers per each child in the home, or who experienced more depressive symptoms as represented by higher scores on the Parent Health Questionnaire - 9 (PHQ-9; Kroenke, Spitzer, \& Williams, 2001) would be more likely to terminate PCIT prematurely.

\section{Exploratory Question 4}

Do therapist factors, treatment characteristics, and/or treatment participation barriers contribute to attrition in PCIT? Are families who have to wait longer before receiving PCIT more likely to terminate therapy prematurely? Do more stressors and obstacles, according to the Barriers to Treatment Participation Scale (BTPS; Kazdin et al., 1997) predict attrition? Does parent and therapist satisfaction with the treatment modality affect attrition?

It was hypothesized that number of weeks from PCIT intake to first CDI teach session would be a predictor of attrition. Greater stressors-obstacles to treatment reported on the BTPS were also hypothesized to be related to increased rates of attrition. Finally, it was hypothesized that parent satisfaction with treatment on the Therapy Attitude Inventory (TAI; Brestan, Jacobs, Rayfield, \& Eyberg, 1999) and therapist satisfaction with treatment on the Treatment 
Implementation Feedback Form (TIFF: Kolko, Herschell, \& Baumann, 2006) would be related to treatment completion.

\section{Method}

\section{Parent Study}

Archival data from children, families, and therapists participating in a larger RO1 study was used (R01 MH095750; A Statewide Trial to Compare Three Training Models for Implementing an EBT; PI: Herschell). The National Institute of Mental Health (NIMH) funded study is being conducted to learn about the best training model for therapists to learn PCIT. This statewide trial is studying which commonly used training models help therapists learn and use PCIT most effectively: cascading, a hierarchical training process focused on two therapists at each agency; distance education, technology-based learning; or learning collaborative, training which addresses multiple organization levels and emphasizes cross-site sharing across teams. The aims of the study are "to build knowledge about training outcomes, to build knowledge about implementation outcomes, and to understand the impact of training [therapists using different training methods] on key client outcomes” (Herschell et al., 2015, p. 1).

\section{Participants}

Participants included 134 parent and child dyads and 36 therapists who were recruited from 21 licensed psychiatric outpatient clinics across one state to participate in the larger research study described above.

Outpatient clinics and the therapists working there were recruited by the research study staff. Inclusion criteria for clinics included: (a) had an outpatient license, (b) were willing to participate in PCIT training, (c) were able to cover site preparation costs, and (d) were agreeable to research participation. Inclusion criteria for therapists included: (a) were currently employed 
at an agency selected to participate in PCIT training, (b) had a masters or doctoral degree in a human services field, (c) were licensed or license eligible and receiving supervision from a licensed individual, (d) were actively seeing children and families appropriate for PCIT, (e) were not previously trained in PCIT and receptive to training, and (f) were amenable to study tasks (e.g., completing assessments, videotaping; Herschell et al., 2015).

Parent-child dyads were recruited by the participating therapists. Therapists were asked to refer all families on their caseload with whom they were using PCIT. Therapists were asked to present all families on their case with a “permission to contact form.” If parent(s) were interested in participating, the parent was instructed by the therapist to provide contact information and sign the form. The therapists then sent the completed "permission to contact form" to the study staff. If parents were not interested in participating, the therapist returned a blank form to the study team so that the study team would have a sense of how many families agreed to participate as well as how many families were approached for participation. Parents who provided contact information and permission were then contacted by a staff member of the research team who completed informed consent and inquired about preferred assessment method (online, mail, phone). Parent-child dyads were excluded only if the child was a ward of the state or living in state custody, according to state laws regarding the right to provide informed consent. Only one child per family could participate in the study.

\section{Procedures}

Therapists completed a battery of assessments online (89\% at baseline) or through the mail (11\%) at four time-points: baseline, 6- (mid), 12- (post), and 24-months (1 year follow-up) as well as a discharge packet about family progress when they felt the family was done (i.e., either completed treatment or a terminated prematurely). The assessments included information 
about their training experiences. The discharge packet completed by the therapist included a summary of the services provided starting with the PCIT Intake session and ending when the family was discharged from PCIT. The report included items like the number of sessions attended, other services the family received from the agency while they participated in PCIT, and the reason PCIT services ended. Data from baseline and 6-month follow-up assessments were used for the current study, as well as data from the discharge packet.

Parents completed a battery of assessments online (60\% at baseline), over the phone (12\%), or through the mail (28\%) at four time points (baseline, 3-, 6-, and 12-months). A family demographic information form was completed at baseline by the parent which included variables such as gender and ethnicity. Child focused assessments included those focused on behavior (e.g., Eyberg Child Behavior Inventory, Vanderbilt ADHD Diagnostic Parent Rating Scale, Social Competence Scale - Parent Version). Parents also completed measures of depression (Parent Health Questionnaire - 9), anxiety (General Anxiety Disorder - 7), parenting practices (Alabama Parenting Questionnaire - 9), an assessment of stressors/obstacles and treatment demands that may interfere with treatment participations (Barriers to Treatment Participation Scale), and a measure of treatment satisfaction (Therapy Attitude Inventory).

Incentives were included at each level. Clinics received free PCIT training for their therapists as well as a small stipend $(\$ 1,000)$ to offset initial startup costs and necessary equipment. Therapists received free training, Continuing Education Credits, and payment for assessment completion (\$25 for baseline and 6-month follow-up, \$30 for 12-month follow-up, and \$40 for 24-month follow-up). Parent-child dyads received payment for each assessment completed (\$20 for baseline and 3-month follow-up, \$30 for 6-month follow-up, and \$40 for 12month follow-up; Herschell et al., 2015). 


\section{Measures}

\section{Demographic Information}

Demographic information for the children and parents was collected using the Demographic Information Form. Demographics collected for the children and parents included items such as age, gender, race/ethnicity, household income, number of children and adults in the home, and parent marital status.

Demographic information for the therapists was collected using the Practitioner Background Form. Demographics collected for therapists included items like age, gender, and race/ethnicity.

\section{Eyberg Child Behavior Inventory}

Child externalizing behavior problems were assessed using the Eyberg Child Behavior Inventory (ECBI; Eyberg \& Pincus, 1999). The ECBI is a parent-report measure for children between 2 to 16 years of age. Each of the 36 items is rated by the parent on two scales: caregivers rate the behavior intensity using a seven-point Likert scale and report whether they consider each behavior as a problem (yes/no). The ECBI has strong reliability and validity. The Intensity Scale has strong test-retest reliability. In a report of test-retest reliability over 10 months, $r=.75$ (Eyberg \& Pincus, 1999). Inter-rater reliabilities for both scales have shown positive correlations; $r=.86$ for the Intensity Scale and $r=.79$ for the Problem Scale (Eyberg \& Pincus, 1999). Weis, Lovejoy, and Lundhal (2005) found positive predictive power for the ECBI components of opposition (.80), conduct problems (.63), and inattention (.85). The ECBI has demonstrated concurrent validity with both the internalizing $(r=.75)$ and the externalizing scales ( $r=.67$ ) on the Child Behavior Checklist (Boggs, Eyberg, \& Reynolds, 1990). 


\section{Depression Scale of the Patient-Health Questionnaire}

The Patient Health Questionnaire-9 (PHQ-9) is the depression module of the PHQ family of diagnostic instruments based on Diagnostic and Statistical Manual of Mental Disorders, $4^{\text {th }}$ Edition (DSM-IV) criteria (Kroenke et al., 2001). The PHQ-9 can establish depressive disorder diagnoses and depressive symptom severity. It is a self-report measure on which parents were asked how often, over the past two weeks, each of the nine core depressive symptoms had bothered them. Response options are "not at all (0)” to “nearly every day (4)”.

The PHQ-9 has evidence supporting its reliability and criterion, construct, and external validity. The assessment has excellent reliability as evidenced by a Cronbach’s alpha of 0.89 and 0.86 and a test-retest kappa of 0.84 over a 48 hour period (Kroenke et al., 2001). The PHQ-9 discriminates well between people with and without major depressive disorder; there is a strong relationship between PHQ-9 scores and scores on other constructs related to depression, and PHQ-9 scores have been found to generalize to different samples (Kroenke et al., 2001).

\section{Barriers to Treatment Participation Scale (BTPS)}

Barriers to treatment participation were measured using an abbreviated version of the Barriers to Treatment Participation Scale (BTPS; Kazdin et al., 1997), a parent scale focused on the caregiver's perceptions of treatment. The BTPS is a 58-item instrument regarding psychological and practical barriers to client engagement and includes two sections. The first 44 items were used for this study and list potential barriers to treatment attendance, participation, and completion (e.g., “Treatment did not seem necessary,” "I felt that treatment cost too much”) and are ordered-category variables with 5 ordered response levels ( 1 = never a problem, 5 = very often a problem). Items 45-58, which list 14 critical events that might have affected treatment participation, were not used for the purposes of this study. The authors have good evidence for 
the internal consistency of the total barriers scores (44 items), as measured by Coefficient Alpha. Cronbach’s Alpha was .86 for the parent version of the scale (Kazdin et al., 1997).

Intercorrelations among the subscales were all positive and in the low-to-moderate range (.21 to .41). The measure also demonstrates convergent validity; terminating prematurely, remaining in treatment, canceling and not showing up for appointments were all predicted from the barriers assessed for in the scale and the barriers-to-treatment model from which the scale was derived. The scale also displayed discriminant validity, as it was not highly related to measures of other competing constructs. The measure adds incremental validity to other measures and constructs that are already known to predict participation in treatment, demonstrating good incremental validity.

\section{Therapy Attitude Inventory}

Parent satisfaction with treatment was assessed using the Therapy Attitude Inventory (TAI; Brestan et al., 1999). The TAI is a 10-item parent-report scale of satisfaction with the process and outcome of PCIT. Questions on the TAI assess confidence in discipline skills, quality of the parent-child interaction, the child's behavior, and overall family adjustment. Parents rate items on a 5-point Likert-type scale, where 1 indicates “dissatisfaction/worsening” of problems and 5 indicates "satisfaction/improvement” of problems. The total score is the sum of all item scores, with a higher total score indicating greater improvement of child behavior problems and satisfaction with treatment. There is good evidence of internal consistency based upon the Cronbach’s Alpha value of .91. The authors also have strong evidence for the test-retest reliability of the TAI, $r=.85$ (Brestan et al., 1999). 


\section{Treatment Implementation Feedback Form}

Therapist satisfaction with PCIT was assessed using the Treatment Implementation Feedback Form (TIFF; Kolko et al., 2006). The TIFF is a 13-item self-report measure completed by clinicians and their supervisors to understand their experiences using an EBT. The version used for the current study was modified to ask about PCIT, specifically. Questions on the TIFF relate to the extent of use, relevance, and helpfulness of and satisfaction with PCIT.

\section{Treatment Summary Report}

A summary of the services provided during the time from the PCIT Intake session to the time the family was discharged from PCIT was assessed using the Treatment Summary Report (TSR). This report was part of a discharge packet that therapists completed when they felt that families were done with treatment; either graduated, prematurely terminated, or left therapy for some other reason. Whether or not the family met mastery in PDI, graduated from PCIT, and were considered a completer or a premature terminator was reported in this form. The report also included items like: family wait time before the CDI teach, CDI coach, PDI teach, and PDI coach; number of sessions attended; child disruptive behavior problems at the last session as represented by ECBI scores; other services the family received from the agency while they participated in PCIT; the therapists' impression about treatment completion; the reason PCIT services ended (e.g., clinical improvement, graduation, family felt that PCIT services were no longer needed, no-shows); and recommendations after discharge.

\section{Results}

\section{Sample Characteristics}

The demographic information form provided descriptive data for overall characteristics of the children and families. The majority of the children were white (71\%) males (66\%) with a 
mean age of 5.35 years $(S D=1.66)$. Parents included were largely white $(78 \%)$ women $(93 \%)$ who were the biological mothers (89\%) of the child receiving PCIT. Parents were 32.82 years old $(S D=9.02)$, on average, and the majority had a high school or college degree $(85 \%)$, and $54 \%$ of families made $\$ 14,999$ or less per year. See Tables 1,2 , and 3 for additional demographics on parents and children. The background form provided descriptive data for overall characteristics of the therapists. Therapists tended to be white (100\%) females (87\%) with a Masters degree $(97 \%)$. They had a mean age of 36.85 years old $(S D=10.62)$ and averaged about 11 years of work experience $(S D=9.74$; see Table 4$)$.

\section{Basis for Variable Choice}

In order to have sufficient power and because of the large number of variables involved, the scope of the current study, the nature of the analyses used, and the number of participants; 10 predictor variables of interest were examined. For a figure outlining the process for selecting variables, see Figure 2. The process for selecting variables included the following:

1. The literature was reviewed, and variables that were significant predictors in previous studies were included as potential variables. The variables chosen for the current study were based on a recent meta-analytic review of 48 studies on attrition in child and adolescent outpatient mental health care (De Haan et al., 2013), as well as five studies of attrition in PCIT (Boggs et al., 2004; Harwood \& Eyberg, 2004; Lanier et al., 2011; Lyon \& Budd, 2010; Werba et al., 2006), and feedback from the thesis committee (A. Gentzler, A. Herschell, \& C. McNeil, personal communication, March 17, 2015). Fifty-three variables were found to be significant predictors of attrition in the meta-analysis (De Haan et al., 2013). One additional predictor of attrition was found in one study included in the meta-analysis as well as one of the PCIT attrition studies. Ten additional variables 
were suggested by the committee. This brought the total number of possible predictors to 64 variables. Of these 64, 14 were pre-treatment child characteristics, 14 were pretreatment parent or family characteristics, and 36 were treatment or therapist factors or treatment participation barriers. Data had been collected on 33 of the 64 variables for the parent study: 10 child variables, eight parent variables, and 15 treatment or therapist variables or barriers to treatment. A list of the 33 variables measured, whether or not they were included, and the reasons for exclusion can be found in Table 5.

2. One variable was excluded because it was believed to be an inadequate measure of the predictor. Four additional variables were excluded from quantitative analyses as the information offered seemed more qualitative, and will be reported as such.

3. The distribution of each variable was examined. For continuous variables, a z-test was applied for normality testing using skewness. If the z-score of the skew variable was greater than 3.29 (Kim, 2013), variables were eliminated. Categorical variables were examined for equal groups. Seventeen of the remaining variables were skewed. Two of those were recoded into categorical variables or new groups and retained while the other 15 were excluded.

4. Intraclass correlations were conducted and examined. If similar variables were correlated with one another at 0.70 or higher, only one was retained. For variables that seemed to belong in the same domain or to be measuring the same construct (e.g., externalizing behavior problems, externalizing diagnosis) only one variable was retained. The final variables included: child gender, ethnic minority status, intensity of externalizing behavior, family income, ratio of caregivers to children in the home, parent depression, wait time for PCIT, number of life stressors and obstacles, parent satisfaction of PCIT, and therapist 
satisfaction of PCIT. All variables examined in the current study are described in Tables 6 and 7. Correlations between predictors are described in Table 8.

\section{Power Analyses}

An a priori power analysis was conducted using G*Power 3.1.3 (Faul, Erdfelder, Buchner \& Lang, 2013) and it was determined that 67 premature terminators would be necessary to gain a power of .80, a medium to large effect size (0.25), and an alpha of .05. In order to compare differences between premature terminators and completers, an approximately equal number of completers was also necessary, for a total minimum of 134 total participants at the family level. The committee for the present study decided that 134 study participants total would be sufficient for the purposes of this study, regardless of whether the premature terminator and completer groups were equal (A. Gentzler, A. Herschell, \& C. McNeil, personal communication, March 17, 2015).

\section{Basis for Analysis Choices}

Descriptive statistics were examined to understand patterns of attrition in PCIT, session by session. Predictors of attrition were examined using Hierarchical Linear Modeling (HLM). Because some families received PCIT from the same therapist and some therapists worked within the same agency, families and therapists were not independent cases. Parent-child dyads with the same therapist shared variance according to their common therapist, and therapists who worked in the same agency shared variance according to their common agency.

HLM, a complex form of ordinary least squares (OLS) regression, can be used to analyze variance in outcome variables when predictor variables are at different hierarchical levels (Woltman, Feldstain, MacKay, \& Rocchi, 2012). HLM takes into consideration both the withinand between-group regressions, allowing for data collected at variable levels of analysis to be 
studied without violating assumptions of independence in linear multiple regression (Woltman et al., 2012).

HLM analyses were implemented through HLM, Version 7 (Raudenbush, Bryk, \& Congdon, 2011) with the 134 individual parent-child dyads at level one. Second-level units were the 36 therapists, and the 21 agencies included in the current study were included at level three.

Additionally, counties and not agencies, therapists, or families, were randomly assigned to three different therapist training methods in the parent RO1 study. Because the purpose of the parent study is to evaluate the effectiveness of the three training models, it was suspected that training condition might impact family outcomes, including attrition. Therefore, HLM models were run with and without the training condition included, in order to take into account the effect of the county and thus the training that each therapist received as part of the parent study. The effects of different training methods were not looked at specifically, as the larger study is still ongoing and blindness to the training condition is important.

\section{Preliminary Analyses}

Because participants of the current study were part of a larger effectiveness trial in which implementation was the focus, the decision of when to discharge a family and whom to consider a completer or premature terminator were based on therapists’ judgment. Therapists were asked both: whether or not each family completed treatment at an agreed upon time as well as whether or not a family graduated from PCIT. Because there was some variability in therapist judgment of attrition (i.e., whether the case was completed at an agreed upon time) and therapist report on the completion the treatment protocol (i.e., whether families graduated), details about discharged families and reasons for attrition reported on the Treatment Summary Form were reviewed. 
Based on this review, nine cases reportedly completed at an agreed upon time but did not graduate from PCIT. Reasons for this discrepancy were examined in order to determine whether or not the cases would be considered completers or premature terminators. According to therapists' reports, one family was discharged because of clinical improvement. Two others were referred to other services because there was no progress or because the problem got even worse. Three additional cases were also referred out because the therapist deemed PCIT as not appropriate for the family, though no increase in problems was reported. Finally, two cases were referred to other services because of logistical issues. One was discharged from partial hospitalization, which is where he/she received PCIT. The other was referred to another agency as his/her parent was employed by the agency at which he/she was receiving PCIT. Each of these nine cases was considered a premature terminator, as therapist report of graduation was used as the measure of treatment completion.

Before the HLM analyses were conducted, an unconditioned model of the variation of attrition was created to predict variation between therapists and agencies regarding family attrition from therapy and therapist and agency-level characteristics. A one-way analysis of variance was performed to confirm the necessity of HLM. Agency (level-3) and therapist (level2) were entered into the model predicting attrition, without any level-1 predictors included. In effect, the variance of the dependent variable, attrition, was partitioned in terms of therapist variance and agency variance. Results indicated that about $13 \%$ of the variance in attrition was at the therapist or agency level and that using HLM to account for that shared variance was necessary.

Data files were prepared using IBM Statistical Package for the Social Sciences (SPSS) before importing the data structure into the HLM software. Separate files were created for each 
predictor variable, including separate files for each level of the data. Level-1, level-2, and level-3 SPSS data sets were then loaded into the HLM software, and the HLM analyses were conducted.

Prior to recoding variables, missing data codes were deleted in order to be formatted to be recognized by HLM. A dummy variable was then created for training condition, by scoring cascading and distance education as one and learning collaborative as zero then scoring cascading and learning collaborative as one and distance education as zero.

\section{Pattern of Attrition}

Of the 134 families in the current study, 98 families (73\%) terminated PCIT prematurely and 36 families (37\%) graduated. It was hypothesized that more families would terminate early in treatment than later in treatment. Descriptive statistics were inspected to understand whether there were specific patterns of attrition as well as to understand whether families terminated treatment at specific times in PCIT (e.g., after CDI teach, during CDI, after PDI teach, or during PDI). Of the families who left therapy prematurely, 14\% dropped out after an assessment session, $10 \%$ after the CDI teach, 61\% after a CDI coach, $2 \%$ after a PDI teach, and 13\% after a PDI coach (See Figure 3). Findings support the hypothesis that families were most likely to drop out early on. Families were more likely to drop out during the CDI coach phase. Families who progressed to PDI teach were more likely to stay in treatment. The majority (53\%) of families who dropped out left treatment after attending 4 or fewer CDI coach sessions, with the largest percentage (16\%) of families dropping out after the second CDI coach session. See Table 9 for the total number of CDI coaches attended and Table 10 for the total number of coach sessions attended by families who left therapy prematurely. See Figure 4 for the number of CDI sessions attended by families who left therapy prematurely. 


\section{Predictors of Attrition \\ Child Characteristics}

The purpose of the second research question was to examine whether certain child characteristics that had been found to correlate with attrition in previous studies significantly predict attrition in PCIT as well. HLM models were run to understand whether specific child characteristics (i.e., male, ethnic minority, more severe externalizing behavior problems) affected attrition. To account for therapists from different counties being randomly assigned to different training conditions, each of the three models was run twice, once without therapist training condition included and once with therapist training condition included (see Table 11 for all HLM results).

Results suggest that gender did not affect attrition, either before (Coefficient $=0.06, S E=$ 0.33, $t=0.17, d f=20, p=0.86$ ) or after (Coefficient $=-0.24, S E=0.43, t=0.55, d f=18, p=$ 0.59) taking into account training condition. Ethnic minority status was also not a significant predictor of attrition without or with (Coefficient $=-0.16, S E=0.63, t=-0.25, d f=18, p=$ 0.80) training condition added to the model. In the HLM model run without therapist training condition, the analyses being conducted by the HLM program were terminated after running for 29 hours and 45 minutes and over 18.2 million iterations without converging. This lack of convergence may have been due to a lack of relationship with attrition. Finally, children with more severe externalizing behavior problems were not significantly more likely to leave therapy prematurely. This was true both before accounting for training condition (Coefficient $=-0.01, S E$ $=0.01, t=-1.09, d f=20)$ and when accounting for therapist training condition (Coefficient $=-$ $0.01, S E=0.01, t=-1.06, d f=18)$. 


\section{Family or Parent Characteristics}

In order to examine whether family income, parent-to-child ratio, and parent depression predicted attrition in PCIT, six additional HLM models were conducted, three with and three without training condition included. Parent depression was not a significant predictor of attrition, either with (Coefficient $=0.01, S E=0.04, t=0.14, d f=18, p=0.84)$ or without $($ Coefficient $=$ 0.01, $S E=0.04, t=0.14, d f=18, p=0.89$ ) therapist training condition included. While a lower parent-to-child ratio in the home did not significantly predict attrition in a model without training condition (Coefficient $=-0.37, S E=0.20, t=-1.85, d f=20, p=0.08$ ), after the variance of therapist training condition was accounted for with the addition of condition to the HLM model, parent-to-child ration was a significant predictor of attrition (Coefficient $=-0.51, S E=0.22, t=$ 2.29, $d f=18, p=0.03)$. This suggests that families with fewer caregivers for each child in the home are more likely to drop out. However, though the inclusion of training condition in the model elucidated the effect of parent-to-child ratio on attrition, it did the opposite for family income. Family income appeared to be a significant predictor of attrition without training condition included (Coefficient $=0.49, S E=0.17, t=2.83, d f=20, p=0.01$ ). However, when therapist training condition was added to the model, the effect of family income was no longer significant (Coefficient $=0.35, S E=0.27, t=1.33, d f=18, p=.20)$. Due to this unexpected result, a one-way ANOVA was conducted to determine whether there was still a relationship between income and condition, even after randomization. Results suggested a significant relationship at the $\mathrm{p}<.01$ level.

\section{Therapist Factors, Treatment Characteristics, and Treatment Participation Barriers}

Finally, four additional HLM models were run to examine whether a longer wait for treatment, more life stressors and obstacles, greater parent satisfaction with PCIT, and greater 
therapist satisfaction with PCIT predicted treatment attrition. Each model was run twice, first without training condition included then with the dummy code for training condition included.

The wait time for treatment, or number of weeks between the family’s PCIT intake session and CDI teach session, did not significantly predict attrition in the model not including therapy training condition (Coefficient $=0.01, S E=0.01, t=0.66, d f=20, p=0.51$ ). However, after condition was included in the model, wait time for PCIT became a significant predictor (Coefficient $=-0.02, S E=0.01, t=-2.49, d f=18, p=0.02)$ such that families who waited a greater number of weeks between their PCIT intake session and CDI Teach session were more likely to leave therapy prematurely. In order to measure the effect of logistical barriers to treatment, the number of life stressors and obstacles reported on the BTPS was examined as a predictor of attrition. A greater number of reported stressors and obstacles significantly predicted attrition both before (Coefficient $=-0.52, S E=0.15, t=-3.49, d f=20, \mathrm{p}<0.01$ ) and after (Coefficient $=-0.66, S E=0.19, t=-3.49, d f=18, \mathrm{p}<0.01)$ therapist training condition was added to the model. Parent ratings of satisfaction with PCIT was also a significant predictor both before (Coefficient $=0.17, S E=0.03, t=5.32, d f=20, \mathrm{p}<0.01)$ and after $($ Coefficient $=0.18$, $S E=0.04, t=5.07, d f=18, \mathrm{p}<.01)$ the variance related to therapist training condition was accounted for. Parents who were less satisfied with PCIT were more likely to leave PCIT before graduating. The final predictor examined in the current study was therapist satisfaction with PCIT. However, neither the model with or without therapist training condition converged. This is possibly due to a lack of relationship with attrition. Therefore, it is unlikely that therapist satisfaction with the treatment modality significantly affected attrition in the current study.

Therapists were asked about their impressions regarding treatment completion on the Treatment Summary Forms. They were asked to indicate whether or not the following issues had 
a negative impact on the overall course and outcome of treatment for each family they treated.

Therapists reported that parent work, family schedules, and being too busy had a negative impact on PCIT for $54.2 \%$ of cases; that $27.3 \%$ of cases were negatively impacted by marital discord/conflict; that severity of parental mental health problems was an issue for $20.5 \%$ of families, and that $18.2 \%$ experienced residential instability (e.g., moves, no phone) that affected PCIT progress. Therapists also reported that PCIT was negatively impacted by conflict with an outside family member/friend (15.9\%), family involvement in other treatment programs that interfered/competed with PCIT services (12.1\%), limited parental cognitive skills (12.1\%) and parent anger or hostility (7.6\%). The parent being out of the home was an issue for $6.8 \%$, (a) drug/alcohol problems(s) affected the course of treatment and outcome for $6.1 \%$ of families, $5.3 \%$ of the children served reportedly had limited cognitive skills, and 3.8\% of the families reported that the child being out of the home affected PCIT course and treatment outcome. Finally, therapists reported having to "childline” a family or report suspected abuse to child welfare for $3.0 \%$ of their PCIT families, that living in a dangerous community was an issue for $0.8 \%$ of the cases, or just one family, and therapists indicated "other” negative impacts on PCIT for $26.5 \%$ of the families they treated (See Table 12).

Therapists reported other negative impacts on treatment including those related to logistical barriers (e.g., parent incarceration, transportation, birth of a new baby); parent resistance or lack of commitment to PCIT (unresponsiveness to coaching, cancellations and noshows); reports that PCIT may not have been the most appropriate course of treatment (e.g., child has limited speech, parent has no behavioral concerns); and other reasons. A list of the reasons reported by therapists and the number of families experiencing these issues can be found in Table 13. 
Therapists were also asked to report why PCIT services ended. The most commonly endorsed reasons were: no-shows (37.3\%); disinterest in PCIT/low motivation (32.1\%); client graduated from treatment (27.6\%); problems got better/clinical improvement (26.3\%); and cancellations (25.4\%). Other reasons endorsed included: family felt PCIT services were no longer needed (23.1\%), therapist felt PCIT services were no longer needed (17.3\%); noncompliance with PCIT by patient and/or family during sessions (16.4\%); schedule conflicts (16.4\%); family or child moved/no longer available/missing (6.0\%); family did not like therapy, therapist, or other aspects of the service (3.8\%); problem got worse/clinical deterioration (3.7\%); legal problems that prevented family’s participation (2.2\%); insurance company or policy constraints/issues (2.2\%); child removed from the home (0.7\%); and other reasons (23.3\%). A list of the reasons and the number of families who left therapy for each reason can be found in Table 14. A list of the other reasons indicated by therapists can be found in Table 15.

Finally, therapists were asked about the recommendations they gave each family after discharge. Therapists were most likely to refer families/children to outpatient treatment (29.1\%), Behavioral Health Rehabilitation Services (BHRS or wraparound; 21.6\%); or intensive case management and resource coordination with face-to-face meetings (14.9\%). Therapists also referred families to community support services (7.5\%), family-based services (6.7\%); family therapy (3.7\%); administrative case management without face-to-face meetings (2.2\%); partial hospitalization or day treatment (2.2\%); and/or other services (20.9\%). A list of treatment recommendations and the number of families recommended for each can be found in Table 16. 


\section{Discussion}

\section{Pattern of Attrition}

The current study had a relatively high rate of attrition (73\%). This was higher than any of the other PCIT studies (50\% to 69\%) but was within the range of attrition rates of child therapies reported in the meta-analysis (28\% to 75\%; De Haan, 2013). A possible reason for the high rate of attrition is because the clinicians included in the current sample were all new to PCIT, reporting on their first cases. The parent study was also an effectiveness and implementation study, which tends to have higher rates of attrition than efficacy studies. Additionally, it is possible that training condition contributed to attrition. Though condition was not examined, to maintain blindness in the parent study, it was controlled for. Findings suggest greater attrition occurred during the CDI Coach phase than in other phases of PCIT. These results supported the hypothesis that more families would terminate early in treatment, which is consistent with previous research (e.g., Kazdin \& Mazurick, 1994; Luk et al., 2001; McCabe, 2002). However, it is unclear whether the attrition was due to the timing in treatment or the content of treatment sessions. Future studies should examine possible reasons for increased attrition in CDI. For example, it is possible that the increased rates of attrition during this phase were due to it being at the beginning of treatment. The literature suggests that attrition often occurs early in treatment (Fernandez et al., 2015; Kazdin \& Mazurick, 1994) and that most premature terminators leave therapy by the fifth or sixth session (Bados et al., 2007; Garfield, 1994). That was true for the current study, as well, as the majority (53\%) of families who dropped out left treatment after attending 4 or fewer CDI coach sessions or 6 total PCIT sessions, including the PCIT intake and the CDI teach session. 
Additionally, an increased number of families may leave during the CDI phase of PCIT because they find CDI effective enough on its own. Perhaps some of the premature terminators experienced sudden gains or rapid response. In fact, rapid response is well-documented in the literature on parent training. In a review of immediate gains in 82 studies over 29 years, Brestan and Eyberg (1998) found an association between immediate gains and parent training. Hakman and colleagues (2009) found that patterns of parent-child interactions improved quickly and considerably during the first three sessions of PCIT with child welfare involved parent-child dyads. Harwood and Eyberg (2006) found significant decreases in parenting stress, increases in positive parenting practices, and decreases in the child's disruptive behavior during CDI alone. Though it is possible that sudden gains and rapid response may be associated with attrition, the literature suggests that both are long-term predictors of better outcomes at treatment termination and at follow-ups (Aderka, Appelbaum-Namdar, Shafran, \& Gilboa-Schechtman, 2011; Haas et al., 2002; Halina, Chorpita, Lee, Weisz, \& The Research Network of Youth Mental Health, 2013; Lackner et al., 2010). Though the dose-effect literature does suggest that at least 11 sessions are necessary for $50 \%$ of clients to make significant treatment gains, some clients will recover in just a few sessions, and other clients may need many more. Because PCIT is very focused on addressing specific problems, it may be effective with fewer sessions. Clients also may be more likely to complete a briefer adaptation of PCIT.

Another possible reason for increased attrition in CDI is the possibility that attrition is partly related to a poor parent-therapist relationship early in treatment. Harwood and Eyberg (2004) found that successful completion of PCIT was predicted by a good parent-therapist relationship early in treatment. The therapeutic relationship was not examined in the current study because the variable was too skewed; most parents rated therapists favorably. 


\section{Child Characteristics}

Contrary to previous research (De Haan et al., 2013), results suggest that child gender did not affect attrition. Ethnic minority status was also not a significant predictor of attrition. While these results supported another study with similar results (Johnson et al., 2009), they also opposed findings from several studies that have found evidence to support that minority status or ethnicity predicts attrition. Minority status was analyzed within at least ten studies with a large number of respondents in the De Haan and colleagues (2013) meta-analysis and was a significant predictor with a small effect size. One of the studies in the meta-analysis, Warnick and colleagues (2012), found that client ethnicity significantly predicted attrition in a sample of 1098 families. Results from Miller and colleagues (2008) suggested that African American youth attended fewer sessions than Caucasian youth, in a sample of over 400 children. Armbruster and Fallon (1994) studied 304 children and adolescents at a large, urban outpatient clinic for child mental health services, and their results also indicated that families with minority children were more likely to terminate prematurely. However, Armbruster and Fallon (1994) also reported that when socioeconomic status (SES) was controlled for, minority status was no longer a significant predictor.

Results of the current study also suggest that children with more severe externalizing behavior problems were not significantly more likely to leave therapy prematurely. While these results contradict some previous findings on greater symptom severity in general and greater externalizing behaviors specifically (Baruch et al., 2009; De Haan et al., 2013; Friars \& Mellor, 2007; Miller et al., 2008; Nock \& Kazdin, 2001), they support another previous study of attrition in PCIT which also found that severity of disruptive behavior was not a significant predictor (Werba et al., 2006). Similarly, Armbruster and Fallon (1994) found that the premature 
terminators and completers in their sample of 304 children seeking treatment at an outpatient clinic were equally psychiatrically impaired. Child characteristics may not predict attrition in the current study because, while PCIT is family focused, it is not child focused. The parent takes a more active role in therapy than does the child, which may explain why child gender, ethnic minority status, and externalizing behavior did not have an effect on attrition.

\section{Family or Parent Characteristics}

Parent depression was not a significant predictor of attrition. This finding contradicts the literature that largely suggests that more parental psychiatric problems (De Haan et al., 2013; Johnson et al., 2009) in general and more parent internalizing problems (De Haan et al., 2013; Meadows, McLanahan, \& Brooks-Gunn, 2007) and depression (Venable \& Thompson, 1998) specifically, predict attrition. Nock and Kazdin (2001) found that, while parental depression did not directly predict attrition, it was associated with lower expectancies and that lower expectancies predicted attrition. Perhaps there is also a mediator in the current sample; or another variable through which parental depression affects attrition. It is also possible that the measure of depression used in the current study was not robust enough to capture depression. Finally, it is likely that parental levels of depression were not severe enough to impact treatment in the current sample. The PHQ has a scale from 0 to 36. The parents in the current sample had a mean score of 8.60, which is relatively low.

It may also be the case that attrition in PCIT is truly not affected by parental depression. This would suggest that PCIT is an acceptable treatment for children of depressed parents, as they are no more likely to leave therapy than non-depressed parents. This opposes the results of a study conducted by Timmer and colleagues (2011) which found that depressed parents were more likely to leave therapy prematurely. However, there was no indication that depressive 
symptoms interfered with PCIT's effectiveness in the depressed parents who stayed in treatment (Timmer et al., 2011). In fact, depressed parents who participated in PCIT not only reported significant positive outcomes, they also reported decreased depressive symptoms (Timmer et al., 2011). This could be partly due to the behavioral activation that is assigned in PCIT; five minutes of positive interaction with their child who is in treatment. Parents who value a positive parent-child interaction may find this rewarding and activating.

While parent-to-child ratio in the home did not significantly predict attrition in a model without training condition, after the variance of therapist training condition was accounted for with the addition of condition to the HLM model, parent-to-child ratio was a significant predictor. Though parent-to-child ratio, specifically, has not been examined in any of the previous studies on attrition that were reviewed, this finding supports previous research suggesting that a greater number of children in the household (De Haan et al., 2013; Johnson et al., 2009) and residing in a single caregiver household (Warnick et al., 2012) predicted attrition. Number of children in the household and single-caregiver households were both correlated with parent-to-child ratio in the current study, as having only one parent and having more children led to a lower ratio. Parent-to-child ratio was examined rather than one of the previously studied variables because it seemed to capture important information regarding both of the previously studied variables and was thought to be more useful information.

Family income appeared to be a significant predictor of attrition without training condition included. However, when therapist training condition was added to the model, the effect of family income was no longer significant. This result was unexpected because randomization of the parent study used an income-related stratification in order to randomize the counties in such a way that there would be no significant differences in income between the three 
training conditions. This resulted in the three least-impoverished counties (based on the percentage of children in the county who qualified for free or reduced school lunches) being randomized to different conditions. Due to this unexpected result, a one-way ANOVA was conducted to determine whether there was still a relationship between income and condition, even after randomization. Results suggested a significant relationship at the $\mathrm{p}<.01$ level. Follow-up analyses showed that, although the counties were correctly randomized, one of the three least-impoverished counties randomized to one training condition had recruited many more families for the parent study than either of the other two counties randomized to the other two conditions. Therefore, training condition was in fact related to income, and the addition of condition to the HLM model for income correctly controlled for the variance accounted for by condition. Because of this high correlation between condition and income, when the training condition was added to the model, the model was also in effect controlled for income. Therefore, the model without training condition and income accounted for was interpreted.

Results suggest that income does predict attrition, with families with lower income being more likely to leave therapy prematurely. Income was selected as a proxy measure of SES for the current study, as a composite measure of SES was not obtained in the parent study. Though the finding that family income predicted attrition failed to support some previous studies (Johnson et al., 2009; McCabe, 2002), research findings regarding SES and attrition are inconsistent. The results contradict another previous study of PCIT by Werba and colleagues (2006), which found that SES was not a significant predictor of attrition in a sample of 50 families. However, two additional studies of attrition in PCIT found SES to predict attrition (Harwood \& Eyberg, 2004; Lanier et al., 2011). Other studies have similarly found that SES is associated with an increased likelihood of treatment attrition. In the 2013 meta-analysis of attrition in child and adolescent 
outpatient mental healthcare by De Haan and colleagues, SES was examined in 20 of the included studies and was found to significantly predict attrition. Some studies included in the meta-analysis in which SES predicted attrition were: (1) a study of another parent management training intervention for parents of 3- to 10-year-olds diagnosed with oppositional-defiant disorder and/or conduct disorder (Peters et al., 2005); (2) children and adolescents referred for oppositional, aggressive, and antisocial behavior (Nock \& Kazdin, 2001); (3) 2- to 7-year-olds in outpatient treatment at 10 different clinics (Garcia \& Wiesz, 2002); and (4) infants, children, and adolescents receiving various treatments at an urban university child guidance clinic (Armbruster \& Fallon, 1994).

\section{Therapist Factors, Treatment Characteristics, and Treatment Participation Barriers}

The wait time for treatment, or number of weeks between the family's PCIT intake session and CDI teach session, did not significantly predict attrition in the model not including therapy training condition. However, after condition was included in the model, wait time for PCIT became a significant predictor. These results supported another PCIT study, a long-term follow-up study of 46 families who received PCIT (Boggs et al., 2004), in which 19\% of the premature terminators reported that one main reason for leaving therapy was that they felt unable to wait for treatment or felt that treatment was progressing too slowly. Warnick and colleagues (2012) also found that longer wait time predicted attrition from services at an urban outpatient mental health clinic. Early attrition, especially, might be due to a long wait time. Parents who feel like they are waiting too long may seek services elsewhere, their child’s behavior may become worse, or the crisis that motivated them to seek treatment may be over. This may be especially true for families with lower SES because of the “crisis-reactive” (Lorion, 1974) nature of poverty. It is also important to note that the reason for longer wait times were not reported. So, 
there are various reasons why families may have had to wait for PCIT. For example, families may have had to wait because there was a long waiting list at the agency, scheduling may have been an issue, or families may have experienced other barriers to treatment participation.

More parent-reported competing activities and life stressors on the BTPS significantly predicted attrition both before and after therapist training condition was added to the model. This result fully supported the De Haan and colleagues (2013) meta-analysis and several individual studies that have found similar results. Two of the five other PCIT studies also found that barriers to treatment or logistical problems (e.g., transportation, childcare for siblings) affected attrition. Though they interpreted the total barriers score rather than the competing activities/life stressors subscale score, Lyon and Budd (2010) also used the BTPS to measure barriers to treatment participation in a sample of 12 families who received PCIT. The BTPS authors typically use the total barriers score in research (Lyon \& Budd, 2010). However, the stressors and obstacles subscale score was used in the current study because logistical barriers (e.g., transportation, scheduling, illness, family crises) were of specific interest. Lyon and Budd (2010) found that completers reported experiencing fewer barriers to treatment than premature terminators. Boggs and colleagues (2004) also looked at barriers to treatment in families receiving PCIT. Families who had left therapy prematurely were asked over the telephone about their reasons for dropping out. The primary reason (35\%) reported was logistical problems such as lack of childcare for siblings or lack of transportation. Another study that used telephone interviews after families prematurely terminated therapy was Prinz and Miller's study of families of 4- to 9-year-olds with antisocial behavior (1994). Most families (86\%) reported reasons for attrition related to their current life situation, including environmental or logistical obstacles. McCabe (2002) conducted in-person interviews with families of 6- to 12-year-olds requesting 
treatment before their first therapy session in an outpatient community mental health clinic then followed them throughout the course of treatment. Families who perceived more barriers to treatment before beginning therapy were more likely to terminate treatment prematurely, after attending just one session.

Parent ratings of satisfaction with PCIT also predicted attrition both before and after the training condition was added to the model. This finding is consistent with previous research on PCIT as well as other interventions. Boggs and colleagues (2004) conducted telephone interviews after families left PCIT, and 16\% of families reported that a primary reason they left therapy prematurely was because they were dissatisfied with the treatment approach or techniques. Lyon and Budd (2010) found that families who completed PCIT showed a trend toward being more satisfied with therapy than families who terminated PCIT prematurely. Two studies found in the De Haan meta-analysis (2013) also examined treatment satisfaction as a predictor of attrition in families with children with antisocial behavior or conduct problems. Prinz and Miller (1994) also interviewed caregivers by phone after they had completed therapy or left prematurely. Attrition was related to greater dissatisfaction with the intervention. Luk and colleagues (2001) conducted two studies comparing two different treatments. Six months after the initial clinical contact, parents were asked to rate their own and their child's satisfaction on a questionnaire. Results suggest that parents who terminated therapy prematurely were more likely to perceive the treatment they received as less organized and report dissatisfaction with treatment services, regardless of which of the two treatments they received.

The final predictor examined in the current study was therapist satisfaction with PCIT. However, neither the model with or without therapist training condition converged. This is 
possibly due to a lack of relationship with attrition. Therefore, it is unlikely that therapist satisfaction with the treatment modality significantly affected attrition in the current study.

\section{Limitations}

The current study had some limitations of note. The first is that the effect of training condition on attrition was not examined. The parent study is still active, so training condition was not included in the current study in order to preserve blindness in the study staff. However, it is hypothesized that therapists in the distance education training condition, who received phone consultations but did not attend face-to-face training, have higher rates of attrition. Though training condition was not included as a predictor, the effect of condition was controlled for by including it in the HLM models. Condition was significantly associated with income and results should be interpreted with this in mind.

Therapist training condition was not the only variable of interest that was not examined. Some variables were not included in analyses because of limited variability. For example, the effect of many therapist variables (e.g., gender/ethnic match, years of experience) on attrition could not be examined because the therapists in the study were too homogenous (92\% white, 83\% female, $54.5 \%$ had less than three years of experience). Parenting practices were also too skewed to use in analyses. Additionally, because of the scope of the current study, the nature of the analyses used, and the number of participants, other variables of interest were also not included in the interest of power. It would be interesting to examine the effect of treatment process variables (e.g., number of timeouts in therapy) and other treatment modality features that are specific to PCIT. Therapist skill level may be an important predictor that was not examined because the data on therapist knowledge and skill was not yet complete for the parent study. 
Another limitation was that the study was based on archival data, so some variables of interest were not measured in the parent study.

Finally, a small limitation of the current was that a composite measure of SES was not included, so income was selected as a proxy. Income is an imperfect measure of SES because SES can be subjective (Diemer, Mistry, Wadsworth, Lopez, \& Reimers, 2013) and because income can fluctuate considerably over the course of a short time period (Oakes \& Rossi, 2003). It has been suggested that measures of SES include income, education, occupation and occupational prestige, household size and composition, other resource-based measures (e.g., labor market, wealth), absolute poverty measures (e.g., family budget measures, neighborhoodlevel indicators of poverty), and relative poverty measures (e.g., income-to-needs ratio, food insecurity). Though the parent study did include measures of income, parent education, family size, and employment status, it did not include a composite measure of SES (Diemer et al., 2013). Income is the most commonly used univariate measure of SES and was used in this study.

\section{Strengths}

Though there are limitations to the current study, there are also several strengths. As previously discussed, the attrition rate in the current study was slightly greater than rates found in previous PCIT studies. This may be partly because the parent study is an effectiveness and implementation study of PCIT. The two previous PCIT studies that were efficacy trials had the lowest rates of attrition of the PCIT studies: 50\% (Harwood \& Eyberg, 2004) and 66\% (Werba et al., 2006). The two previous PCIT effectiveness trials had higher attrition rates of 67\% (Lyon \& Budd, 2010) and 69\% (Lanier et al., 2011). While efficacy studies have consistently evidenced lower attrition rates, they also have much more restricted conditions (e.g. a more selective range of clients and therapists) and are often highly dissimilar from real-world experiences and 
settings. Effectiveness trials tend to have higher rates of attrition but are also more generalizable. A strength of the current study that it is an effectiveness trial; and that attrition is described in a real-world sample of diverse children, families, and community therapists in various settings.

A related, central strength of the study is its size and breadth. With a sample of 134 families, it includes a larger sample than any previously published study of attrition in PCIT. Because of the size and scope of the parent study, the current study also includes a relatively diverse sample of children, families, and therapists from 21 different agencies across an entire state. Thus, results of the current study may be more easily generalizable to other PCIT populations. Additionally, the current study is an active study rather than a chart review. Thus, the findings are current and relevant.

Previous studies on attrition in PCIT have largely focused on parent and family characteristics, such as low SES and maternal characteristics. Another strength of this study is that, while it examined some of these same variables, it also examined child factors, therapist factors, treatment characteristics, and treatment participation variables. The literature indicates that many barriers to treatment participation, including practical obstacles related to participation, play a significant role in treatment attrition. While previous PCIT studies (Boggs et al., 2004; Lyon \& Budd, 2010) have examined the impact of barriers to treatment on attrition, Boggs and colleagues (2004) measured barriers to treatment participation by interviewing parents about their reasons for leaving therapy prematurely and included only qualitative data regarding these barriers. While this gathers useful information, it might be interpreted with caution because of social desirability bias. The current study examined barriers to treatment quantitatively, using the BTPS, and analyzed whether they were a statistically significant predictor of attrition. The measure has strong psychometrics (Kazdin et al., 1997). Lyon and 
Budd (2010) also used the BTPS to assess barriers to treatment. They included the total score to examine whether barriers, overall, predicted attrition. The current study looked at a specific subscale of that measure focused on stressors and obstacles that compete with treatment because logistical barriers were of particular interest.

Other studies did not include perceptions of barriers from multiple sources. A strength of the current study was that the BTPS was used and that qualitative data regarding barriers to treatment participation and outcomes was also collected from the therapists as well. Future research should examine whether reports of barriers to treatment are consistent across parents, therapists, and other raters. Like previous PCIT studies, factors related to attrition were also examined qualitatively, though from the therapist perspective rather than the parent perspective. A strength of the current study is the wealth of information collected on the Treatment Summary Report after families graduated from or left therapy prematurely. Feedback from therapists included information regarding services provided, treatment process variables, length and content of treatment, therapist perceptions of treatment outcomes, and impressions about treatment completion.

In addition to data regarding barriers to treatment, the parent study included a wealth of data on children, parents and families, and therapists. Therefore, the current study was also able to study therapist factors on attrition. Though therapist satisfaction with PCIT did not significantly predict attrition, this lack of a relationship is still useful information. Though not measured in the current study, it would be interesting for future research to examine the impact of therapist skill level in PCIT on family attrition. 


\section{Future Research}

Future studies should examine therapist skill level and other variables that may affect attrition. Certain child and parent variables that need further exploration are parenting practices and the diagnosis or symptoms that the child is experiencing. In the current study, therapists reported that some of the families left therapy prematurely because they did not seem appropriate for PCIT. PCIT was designed to be used with preschoolers with disruptive behavior disorders. It has also been found effective with families who have experienced physical abuse (Chaffin, Funderburk, Bard, Valle, \& Gurwitch, 2011) and has been adapted for and studied with various other populations (e.g., Lyon et al., 2009; Masse, McNeil, Wagner, \& Quetsch, 2016;

McDiarmid \& Bagner, 2005; Pincus, Eyberg, \& Choate, 2005). Future studies should continue to test the effectiveness of PCIT with other populations and determine which populations it is effective for so that inclusion and exclusion criteria can be determined and communicated for use in community settings.

Other therapist characteristics, therapy process variables, and specific barriers to treatment participation should also be examined in PCIT, specifically. Some include negative perceptions about treatment, poor therapeutic alliance, whether or not and to what degree families were receiving other psychotherapy services simultaneously, and therapist skill level. Future PCIT studies should examine the effect of the parent-therapist relationship early in treatment, as did Harwood and Eyberg (2004), to possibly replicate the findings that attrition is related to poor parent-therapist relationship early in treatment. The impact of PCIT process variables should also be examined. For instance, it might be interesting to look at how the use and frequency of the timeout procedure and the timeout room might affect attrition in some families. Other specific logistical barriers should also be studied (e.g., lack of childcare, lack of 
transportation, illness, pregnancy, weather). Conducting research in which these barriers are better understood is an important next step. There are currently projects underway that are examining whether incentivizing treatment might increase attendance, reduce attrition, and increase outcomes in PCIT (Quetsch, 2015). Studies on the effects of providing childcare, transportation, and reducing other barriers in PCIT should also be conducted. HLM also allows for cross-level interaction to be examined. Future studies should explore the effect of interactions on attrition in PCIT. For example, Lorion’s (1974) “crisis-reactive” model would suggest that SES and wait time may interact to increase attrition.

Future research should examine possible reasons for increased attrition in the CDI phase. Families leave therapy prematurely at different stages, though often they do so early in treatment (Fernandez et al., 2015; Kazdin \& Mazurick, 1994; Luk et al., 2001; McCabe, 2002). Future research should identify factors that affect early attrition, specifically. One area for further PCIT research is whether CDI is effective enough on its own and whether sudden gains or rapid response affect attrition. Harwood and Eyberg (2006) found significant decreases in parenting stress, increases in positive parenting practices, and decreases in the child's disruptive behavior during CDI. Danko, Garbacz, and Budd (2016) also found that families who completed only CDI experienced early treatment benefits. In an early study examining the components of PCIT, however, Eisenstadt, Eyberg, McNeil, Newcomb, and Funderburk (1993) found that PDI was necessary for reducing noncompliance and disruptiveness. In this study, some families were offered CDI before PDI and some families were offered PDI before CDI. At mid-treatment, those who had experienced PDI reported greater reductions in noncompliance and disruptiveness. At the end of treatment, the PDI-first group reported greater treatment satisfaction. Further component research should be conducted to determine which treatment 
elements are mandatory for outcomes. Goldfine, Wagner, Branstetter, and McNeil (2008) suggested developing and studying a "bare bones" version of PCIT for community agencies with low budgets. To do so, the most effective characteristics of CDI and PDI (financially and behaviorally) need to be revealed and used to develop an adapted form of PCIT.

Novel delivery methods may help reduce attrition in PCIT and should be studied. Flexible scheduling, abbreviated formats, and group or in-home therapy may decrease attrition substantially. However, when adapting PCIT it is imperative to maintain its core defining features and the theoretical and empirical foundation (Eyberg, 2005). Allowing for flexible scheduling may reduce barriers to treatment for both families and therapists for whom a once-aweek session schedule is not flexible enough. McNeil and Hembree-Kigin (2010) suggested a model in which treatment centers could offer PCIT walk-in clinics and offer different PCIT therapy sessions on several different days and times throughout the week. This flexibility would allow families to choose a time that works for their schedule each week and possibly allow therapists to serve a greater number of clients (McNeil \& Hembree-Kigin, 2010). This type of treatment delivery, other types of flexible scheduling, and their effects on treatment attrition should be examined in PCIT.

Abbreviated versions of PCIT should also be further examined. Franco, Soler, and McBride (2005) found that, though efficacy trials of PCIT usually last 12 to 14 sessions before graduation, reaching mastery criteria in and graduating PCIT in community settings can take longer than anticipated. This can make it difficult to keep families interested and motivated to complete PCIT (Franco et al., 2005). Abbreviated treatments may increase treatment retention and completion. There have been a few studies of abbreviated versions of PCIT. Berkovits, O’Brien, Carter, and Eyberg (2010) implemented two abbreviated versions of PCIT in a primary 
care setting. One was a four-session, preventive group intervention and the other included written materials describing PCIT steps and guidelines. Each of the interventions was offered to families who had a child with subclinical behavior problems in which the mothers reported wanting help for their child's behavior. Results suggest decreases in child problem behaviors and ineffective parenting strategies and increases in parental feelings of control in both groups. This suggests that brief versions of PCIT are promising for subclinical populations (Berkovits et al., 2010).

Nixon, Sweeney, Erickson, and Touyz (2003) also tested an abbreviated version of PCIT and compared it to standard PCIT. They used didactic videotapes for the CDI and PDI teach sessions and five face-to-face sessions alternated with five 30-minute telephone consultations to deliver PCIT. Parents reported significant differences in child externalizing behavior, parental stress, and discipline practices for both groups. Though standard PCIT seemed to have better outcomes immediately after therapy, the two groups were comparable by a 6-month follow-up (Nixon et al., 2003). Treatment gains were maintained for both treatment conditions at one and two year follow-ups (Nixon, Sweeney, Erickson, and Touyz, 2004). This suggests that an abbreviated form of PCIT has short- and long-term benefits for clinical populations (Nixon et al., 2003; Nixon et al., 2004).

Graziano and colleagues (2015) have also examined the effectiveness, acceptability, and feasibility of an intensive but abbreviate version of PCIT. This adaptation included completing treatment over a two week period, with 90-minute sessions daily for five days each week. Results suggest that all 11 families who participated completed the intervention and had exceptionally high attendance. Parents reported high rates of treatment satisfaction, reduced externalizing problems, decreased parenting stress, and had improved parenting skills. Treatment 
gains were maintained at a four-month follow-up. Results suggest that a brief and intensive format of PCIT is feasible and effective (Graziano et al., 2015). These and other abbreviated forms of PCIT should be studied further.

Other adaptations to PCIT that should be further studied are in-home PCIT and group PCIT. Offering PCIT services in the home would be expected to overcome many barriers to treatment participation and to decrease attrition. This should be further examined. There are current efforts to implement in-home PCIT, some throughout an entire state (Beveridge et al., 2015). Their findings on its effects on attrition will be important. Offering PCIT in a group format is another suggestion to decrease attrition. One study of group-based PCIT found that parents in the group received support, acceptance, and social reinforcement from other group members, in and out of session (Niec, Hemme, \& Yopp, 2004). The researchers suggested that this high level of cohesiveness may have not only helped to facilitate treatment gains and generalize parent skills to the home but may have also increased treatment adherence (Niec et al., 2004). Perhaps group support helped families to overcome certain barriers to treatment. Future studies should examine this and the effect of group PCIT on attrition. Group therapy can also increase efficiency and reduce costs. Other suggested areas of study include assessments to regularly assess for barriers to treatment participation, satisfaction, and other risks for treatment attrition. Techniques to increase engagement and decrease attrition should also be studied, in general, and in PCIT specifically.

\section{Implications and Clinical Recommendations}

The results of the current study support the use of certain clinical recommendations and engagement strategies. Findings suggest that decreasing wait time, continually assessing and attempting to increase parent satisfaction, and providing additional support to families with more 
life stressors/obstacles, including lower parent/child ratio (e.g., childcare), may help increase treatment completion. Results also suggest that PCIT may be an appropriate treatment for children of parents with depression, as parental depression did not significantly affect attrition in the current sample. Perhaps this is due to the active role parents are asked to take in PCIT. Depressed parents who value a positive relationship with their child who is in PCIT may also find the weekly homework to spend positive time with their child each day rewarding and activating.

Because families were more likely to leave therapy prematurely in the beginning stages of treatment, strategies to elicit engagement early in therapy may be useful. One method, suggested by Barrett and colleagues (2008), is role induction. Role induction usually occurs during a one-hour session before therapy begins and includes strategies to educate clients about expectations for treatment, treatment process, and duration. It has been shown to improve attendance and reduce attrition rates (Walitzer, Dermen, \& Connors, 1999). Role induction can also be conducted during a therapy session. Previous research has displayed the effectiveness of brief role induction via videotape (12 minutes; Reis \& Brown, 2006) and the association between decreases in attrition and use of videotaped role induction (Walitzer et al., 1999). Short videos of role induction may be especially useful in community-based clinics in which time is an issue, wait time for therapy can be long, and clients sometimes complete an intake or therapy orientation with someone other than their primary therapist. The first therapy session of PCIT, the CDI teach, includes many of the strategies that are used in RI. However, PDI is not discussed at great length and it is difficult to clarify expectations regarding length of therapy due to treatment progression being contingent on mastery criteria. Also, because longer wait time for treatment is also a predictor of attrition and long waiting lists can be common, especially in 
community settings, perhaps it would help helpful for role induction to occur earlier, before treatment.

Longer time between the PCIT intake and the first therapy session was associated with a higher likelihood of leaving therapy prematurely. This suggests that anything that can be done to reduce the length of time a person has to wait before beginning PCIT is likely to reduce attrition. If it is not possible to get a family in for therapy immediately, initiating other contact while the family waits and responding promptly to contact from the family is important. It may be useful to have orientation sessions for PCIT families in which individual families or groups of families complete role induction with a therapist or other clinic staff.

Barrett and colleagues (2008) have also suggested that, in order to decrease attrition rates, therapists conduct brief phone interviews with families a few days after the first contact. This offers the family immediate attention; enhances their perception of therapist/agency responsiveness; and allows the therapist to review the presenting concerns, complete role induction with the client, and build rapport.

Often, families seek treatment when there is an immediate need. However, if and when the severity and immediacy of the problem decreases and/or other crises emerge, families may leave treatment prematurely to attend to other, more pressing needs. Limiting wait times for treatment and/or maintaining communication during the waiting period may keep families focused on what led them to seek treatment and keep them engaged and committed to completing therapy. This may be especially important for lower SES families, according to the “crisis-reactive” nature of poverty (Lorion, 1974). Therefore, it might be especially effective to use a treatment approach in which an intake session is offered before the first session. Additionally, it is important that therapists be aware of the barriers to treatment that are 
experienced by low SES families. In fact, Lorion (1974) found that educating therapists in the hardships of poverty, social class, and ethnicity decreased attrition almost as much as client pretherapy preparation.

Many barriers to treatment participation include logistical barriers such as scheduling problems, transportation issues, bad weather, illness, childcare, and other life stressors. While low SES families may experience these barriers at a higher rate, logistical barriers are experienced across all populations. The current study found that more reported life stressors/obstacles significantly predicted attrition. Therapists also reported that parent work, family schedules, and being busy; marital discord/conflict; residential instability; participation in other treatment; parent incarceration; transportation; and pregnancy or the birth of a new baby had a negative impact on the course of PCIT and/or the treatment outcome. Families with a lower parent-to-child ratio were also significantly more likely to leave therapy prematurely. Families with more children and fewer caregivers may experience greater barriers to treatment, such as lack of childcare. As previously suggested, the effects of providing childcare and transportation, of offering incentives to attend sessions, and novel delivery methods should be examined and implemented, if effective. Barriers to treatment should be assessed and discussed frequently. Therapists should help families problem-solve regarding barriers to treatment participation and families experiencing many barriers should be offered additional support and flexibility, if possible. Time-limited or shorter versions of PCIT should also be examined for effectiveness, as certain barriers may be attenuated by altering aspects of treatment delivery.

Therapists reported that parent work schedules, family schedules and being too busy for treatment had negative impacts on PCIT for $54.2 \%$ of cases. Additionally, therapists reported that schedule conflicts (16.4\%), no-shows (37.3\%), and cancellations (25.4\%) were some of the 
reasons why PCIT ended. These issues can lead to families attending fewer PCIT sessions than are needed to graduate. While research shows better outcomes, in general, for families who complete and graduate from PCIT (Danko et al., 2016), there is also evidence that rapid response can occur in PCIT (Hakman et al., 2009; Harwood \& Eyberg, 2006) and that shortened adaptations of PCIT may also be effective (Franco et al., 2005; Nixon et al., 2003). Time-limited or ultra-brief, intensive versions of PCIT need further examination, but may be good solutions for families who find it difficult to attend one hour sessions each week for 12 to 14 weeks. Sledge, Moras, Harley, and Levine (1990) suggested that time-limited therapy has a lower attrition rate than long-term psychotherapy. Shapiro and colleagues (2003) found that planned ultra-brief treatments (two sessions and one follow-up) can be as effective, particularly for less severe clients. Rates of attrition may decrease when duration of PCIT is adapted to be in line with families’ actual usual use of services.

Motivation for treatment is also important for treatment retention and completion. Therapists in the current study reported that parent resistance and lack of commitment to treatment negatively impacted the course and outcome of therapy. Swift and Greenberg (2012) suggest that enhancing motivation for treatment by directly addressing motivation from session to session and using motivational interviewing may decrease attrition. Motivational Interviewing (MI; Miller \& Rollnick, 1991) focuses on helping clients understand and resolve any ambivalent feelings toward treatment and use internal motivation to make behavior changes. MI can increase engagement, which can lead to decreased attrition. MI has been adapted to brief formats, which can be easily integrated into intake evaluations and existing treatments (Rollnick, Heather, \& Bell, 1992). In a study of a brief MI used in the initial intake evaluation of substance abuse, Carroll, Libby, Sheehan, \& Hyland (2001) found a substantial increase in the likelihood of 
treatment initiation. In fact, the effect of MI has already been examined in PCIT. In a study of a combined motivation and PCIT therapy package at a child welfare parenting center, results suggested a reduction in child welfare recidivism (Chaffin et al., 2011) and improved retention (Chaffin et al., 2009). However, the benefits of the addition of the motivational orientation were found only in families with low to moderate initial levels of motivation. The motivation orientation actually had negative effects for families with high initial motivation. This suggests that selective use of motivational interviewing or a motivational orientation may decrease attrition in PCIT.

Therapists reported that PCIT ended for 3.8\% of families because they did not like therapy, the therapists, or other aspects of services. Additionally, 7.6\% of therapists reported that parent anger or hostility had a negative impact on the course and outcome of treatment. Though these numbers seem small, they may be an underestimation. Research suggests that clients tend to not share negative feelings and that therapists are aware of very little of the things clients do not say (17\%; Regan \& Hill, 1992). This may be especially true in PCIT, as most of parenttherapist interactions occur from another room and over an ear piece. Therefore, it is important that PCIT therapists remain sensitive to negative parent feelings and address dissatisfaction with treatment and repair ruptures in the therapeutic bond as soon as they occur. PCIT therapists are trained to have five-minute check-ins with parents at the beginning of sessions each week and they should assess for treatment satisfaction during this time. Because parents may not disclose any negative feelings so openly, it might be useful to assess for client satisfaction and alliance before or after each session in addition to tracking treatment progress weekly (using the ECBI). Though PCIT already includes several strategies to decrease attrition (e.g., providing education about the treatment modality during the first therapy session, checking in with the 
parent at the beginning of therapy weekly, tracking and providing feedback on treatment

progress weekly, and the development of excellent rapport), high attrition rates in PCIT are still a problem. More needs to be done to identify reasons for attrition and to increase retention in PCIT. In order to decrease rates of attrition, it might be useful to consider brief or intensive models of treatment for certain populations. A treatment approach in which role induction and/or other supportive services are offered before the first session, when therapy cannot begin immediately, is also suggested. Brief MI could also be used to increase motivation and decrease attrition.

\section{Conclusion}

Attrition is a significant problem in psychotherapy in general, and PCIT specifically. The current study suggests that lower family income, lower parent-to-child ratio, longer wait time for PCIT, more life stressors, and lower parent satisfaction with PCIT all predict attrition. PCIT has been found to be highly effective. However, attrition reduces the effectiveness of PCIT and other treatments. Future research should focus on predicting and reducing attrition in PCIT. Increases in treatment retention may help to improve therapy outcome even more than additional efficacy studies or developing new treatments. 


\section{References}

References marked with an asterisk indicate studies included in the meta-analysis. The in-text citations to studies selected for meta-analysis are not preceded by asterisks.

Aderka, I. M., Appelbaum-Namdar, E., Shafran, N., \& Gilboa-Schechtman, E. (2011). Sudden gains in prolonged exposure for children and adolescents with posttraumatic stress disorder. Journal of Consulting and Clinical Psychology, 79, 441-446.

Aebi, M., Plattner, B., Metzke, C. W., Bessler, C., \& Steinhausen, H.-C. (2013). Parent- and selfreported dimensions of oppositionality in youth: Construct validity, concurrent validity, and the prediction of criminal outcomes in adulthood. Journal of Child Psychology and Psychiatry, 54, 942-949.

*Armbruster, P., \& Fallon, T. (1994). Clinical, sociodemographic, and systems risk factors for attrition in a children's mental health clinic. American Journal of Orthopsychiatry, 64, 577-585.

Bados, A., Balaguer, G., \& Saldana, C. (2007). The efficacy of cognitive-behavioral therapy and the problem of drop-out. Journal of Clinical Psychology, 63, 585-592.

Barrett, M. S., Chua, W.-J., Crits-Christoph, P., Gibbons, M. B., Casiano, D., \& Thompson, D. (2008). Early withdrawal from mental health treatment: Implications for psychotherapy practice. Psychotherapy (Chic), 45, 247-267.

Baruch, G., Vrouva, I., \& Fearon, P. (2009). A follow-up study of characteristics of young people that dropout and continue psychotherapy: Service implications for a clinic in the community. Child and Adolescent Mental Health, 14, 69-75. 
Berkovits, M. D., O'Brien, K. A., Carter, G. C., \& Eyberg, S. M. (2010). Early identification and intervention for behavior problems in primary care: A comparison of two abbreviated versions of parent-child interaction therapy. Behavior Therapy, 41, 375-387.

Beveridge, R. M., Fowles, T. R., Masse, J. J., McGordon, L., Smith, M. A., Parrish, B. P., Circo, G., \& Widdoes, N. (2015). State-wide dissemination and implementation of parent-child interaction therapy (PCIT): Application of theory. Children and Youth Services Review, 48, 38-48.

Boggs, S. R., Eyberg, S. M., Edwards, D. L., Rayfield, A., Jacobs, J., Bagner, D., \& Hood, K. K. (2004). Outcomes of Parent-Child Interaction Therapy: A comparison of treatment completers and study dropouts one to three years later. Child \& Family Behavior Therapy, 26, 1-22.

Boggs, S. R., Eyberg, S. M., \& Reynolds, L. A. (2010). Concurrent validity of the Eyberg child behavior inventory. Journal of Clinical Child Psychology, 19, 75-78.

Brestan, E., \& Eyberg, S. (1998). Effective psychosocial treatments of conduct-disordered children and adolescents: 29 years, 82 studies, and 5272 kids. Journal of Clinical Child Psychology, 27, 180-189.

Brestan, E., Jacobs, J., Rayfield, A., \& Eyberg, S. M. (1999). A consumer satisfaction measure for parent-child treatment and its relationship to measures of child behavior change. Behavior Therapy, 30, 17-30.

Carroll, K. M., Libby, B., Sheehan, J., \& Hyland, N. (2001). Motivational interviewing to enhance treatment initiation in substance abusers: An effectiveness study. The American Journal on Addictions, 10, 335-339. 
Chaffin, M., Funderburk, B., Bard, D., Valle, L. A., \& Gurwitch, R. (2011). A combined motivation and parent-child interaction therapy package reduces child welfare recidivism in a randomized dismantling field trial. Journal of Consulting and Clinical Psychology, 79, 84-95.

Chaffin, M., Valle, L. A., Funderburk, B., Gurwitch, R., Silovsky, J., Bard, D., McCoy, C., \& Kees, M. (2009). A motivational intervention can improve retention in PCIT for lowmotivation child welfare clients. Child Maltreatment, 14, 356-368.

*Chasson, G. S., Vincent, J. P., \& Harris, G. E. (2008). The use of symptom severity measured just before termination to predict child treatment dropout. Journal of Clinical Psychology, 64, 891-904.

Copeland, W. E., Shanahan, L., Costello, J. E., \& Angold, A. (2009). Childhood and adolescent psychiatric disorders as predictors of young adult disorders. Archives of General Psychiatry, 66, 764-772.

Costello, J. E., Copeland, W. E., \& Angold, A. (2011). Trends in psychopathology across the adolescent years: What changes when children become adolescents, and when adolescents become adults? Journal of Child Psychology and Psychiatry, 52, 1015-1025.

Danko, C. M., Garbacz, L. L., \& Budd, K. S. (2016). Outcomes of parent-child interaction therapy in an urban community clinic: A comparison of treatment completers and dropouts. Children and Youth Services Review, 60, 42-51.

Davis, M. J., \& Addis, M. E. (1999). Predictors of attrition from behavioral medicine treatments. Annals of Behavioral Medicine, 21, 339-349. 
De Haan, A. M., Boon, A. E., de Jong, J. T. V. M., Hoeve, M., \& Vermeiren, R. R. J. M. (2013). A meta-analytic review on treatment dropout in child and adolescent outpatient mental health care. Clinical Psychology Review, 33, 698-711.

Diemer, M. A., Mistry, R. S., Wadsworth, M. E., Lopez, I., \& Reimers, F. (2013). Best practices in conceptualizing and measuring social class in psychological research. Analyses of Social Issues and Public Policy, 13, 77-113.

*Dierker, L., Nargiso, J., Wiseman, R., \& Hoff, D. (2001). Factors predicting attrition within a community initiated system of care. Journal of Child and Family Studies, 10, 367-383.

Eisenstadt, T. H., Eyberg, S., McNeil, C. B., Newcomb, K., \& Funderburk, B. (1993). Parentchild interaction therapy with behavior problem children: Relative effectiveness of two stages and overall treatment outcome. Journal of Clinical Child Psychology, 22, 42-51.

Eyberg, S. M. (2005). Tailoring and adapting parent-child interaction to new populations. Education and Treatment of Children, 28, 197-201.

Eyberg, S. M., Nelson, M. M., \& Boggs, S. R. (2008). Evidence-based psychosocial treatments for children and adolescents with disruptive behavior. Journal of Clinical Child \& Adolescent Psychology, 37, 215-237.

Eyberg, S. \& Funderburk, B. (2011). Parent-Child Interaction Therapy protocol. Gainesville, FL: PCIT International Publishing.

Eyberg, S. M., Nelson, M. M., Duke, M., \& Boggs, S. R. (2005). Manual for the parent-child interaction coding system ( $3^{\text {rd }}$ ed.).

Eyberg, S. M., \& Pincus, D. (1999). Eyberg Child Behavior Inventory and Sutter-Eyberg Student Behavior Inventory-Revised: Professional manual. Odessa, FL: Psychological Assessment Resources. 
Faul, F., Erdfelder, E., Buchner, A., \& Lang, A.-G. (2013). G*Power Version 3.1.7 [computer software]. Uiversität Kiel, Germany. Retrieved from http://www.softpedia.comget/Science-CAD/G-Power.shtml

Fernandez, E., Salem, D., Swift, J. K., \& Ramtahal, N. (2015). Meta-analysis of dropout from Cognitive Behavioral Therapy: Magnitude, time, and moderators. Journal of Consulting and Clinical Psychology, 83, 1108-1122.

*Flicker, S. M., Turner, C. W., Waldron, H. B., Brody, J. L., \& Ozechowski, T. J. (2008). Ethnic background, therapeutic alliance, and treatment retention in functional family therapy with adolescents who abuse substances. Journal of Family Psychology, 22, 167-170.

Franco, E., Soler, R. E., \& McBride, M. (2005). Introducing and evaluating parent-child interaction therapy in a system of care. Child and Adolescent Psychiatric Clinics of North America, 14, 351-366.

*Friars, P. M., \& Mellor, D. J. (2007). Drop out from behavioral management training programs for ADHD: A prospective study. Journal of Child and Family Studies, 16, 427-441.

*Garcia, J. A., \& Weisz, J. R. (2002). When youth mental health care stops: Therapeutic relationship problems and other reasons for ending youth outpatient treatment. Journal of Consulting and Clinical Psychology, 70, 439-443.

Garfield, S. L. (1994). Research on client variables in psychotherapy. In A. E. Bergin \& S. L. Garfield. (Eds.), Handbook of psychotherapy and behavior change (pp. 190-228). New York, NY: Wiley.

Goldfine, M. E., Wagner, S. M., Branstetter, S. A., \& McNeil, C. B. (2008). Parent-child interaction therapy: An examination of cost-effectiveness. Journal of Early and Intensive Behavior Intervention, 5, 119-141. 
Graziano, P. A., Bagner, D. M., Slavec, J., Hungerford, G., Kent, K., Babinski, D., Derefinko, K., \& Pasalich, D. (2015). Feasibility of intensive parent-child interaction therapy (IPCIT): Results from an open trial. Journal of Psychopathology and Behavioral Assessment, 37, 38-49.

*Gunnarsdottir, T., Njardvik, U., Olafsdottir, A. S., Craighead, L. W., \& Bjarnason, R. (2011). The role of parental motivation in family-based treatment for childhood obesity. Pediatric Obesity, 19, 1654-1662.

Haas, E., Hill, R. D., Lambert, M. J., \& Morrell, B. (2002). Do early responders to psychotherapy maintain treatment gains? Journal of Clinical Psychology, 58, 1157-1172. Hakman, M., Chaffin, M., Funderburk, B., \& Silovsky, J. F. (2009). Change trajectories for parent-child interaction sequences during parent-child interaction therapy for child physical abuse. Child Abuse \& Neglect, 33, 461-470.

Halina, J. D., Chorpita, B. F., Lee, S., Weisz, J. R., The Research Network of Youth Mental Health. (2013). Sudden gains as a long-term predictor of treatment improvement among children in community mental health organizations. Behaviour Research and Therapy, 51, 564-572.

Harwood, M. D., \& Eyberg, S. M. (2004). Therapist verbal behavior early in treatment: Relation to successful completion of Parent-Child Interaction Therapy. Journal of Clinical Child and Adolescent Psychology, 33, 601-612.

Harwood, M. D., \& Eyberg, S. M. (2006). Child-directed interaction: Prediction of change in impaired mother-child functioning. Journal of Abnormal Child Psychology, 34, 335-347.

Hatchett, G. T., \& Park, H. L. (2003). Comparison of four operational definitions of premature termination. Psychotherapy: Theory, Research, Practice, Training, 40, 226-231. 
*Hawley, K. M., \& Weisz, J. R. (2005). Youth versus parent working alliance in usual clinical care: Distinctive associations with retention, satisfaction, and treatment outcome. Journal of Clinical Child \& Adolescent Psychology, 34, 117-128.

Hayes, A. M., Laurenceau, J., Feldman, G., Strauss, J. L., \& Cardaciotto, L. (2007). Change is not always linear: The study of nonlinear and discontinuous patterns of change in psychotherapy. Clinical Psychology Review, 27, 715-723.

Herschell, A. D., Kolko, D. J., Scudder, A. T., Taber-Thomas, S., Schaffner, K. F., Hiegel, S., Iyengar, S., Chaffin, M., \& Mrozowski, S. (2015). Protocol for a statewide randomized controlled trial to compare three training models for implementing an evidence-based treatment. Implementation Science, 10, 1-16.

Ilardi, S. S., \& Craighead, W. E. (1994). The role of nonspecific factors in cognitive-behavioral therapy for depression. Clinical Psychology: Science and Practice, 1, 138-156.

*Johnson, E., Mellor, D., \& Brann, P. (2009). Factors associated with dropout and diagnosis in child and adolescent mental health services. Australian and New Zealand Journal of Psychiatry, 43, 431-437.

Kataoka, S. H., Zhang, L., \& Wells, K. B. (2002). Unmet need for mental health care among US children: Variation by ethnicity and insurance status. American Journal of Psychiatry, 159, 1548-1555.

Kazdin, A. E. (1995). Conduct disorders in childhood and adolescence ( $2^{\text {nd }}$ ed.). Thousand Oaks, CA, US: Sage Publications.

Kazdin, A. E., Holland, L., Crowley, M., \& Breton, S. (1997). Barriers to treatment participation scale: Evaluation and validation in the context of child outpatient treatment. Child Psychology \& Psychiatry \& Allied Disciplines, 38, 1051-1062. 
Kazdin, A. E., \& Mazurick, J. L. (1994). Dropping out of child psychotherapy: Distinguishing early and late dropouts over the course of treatment. Journal of Consulting and Clinical Psychology, 62, 1069-1074.

*Kazdin, A. E., \& Wassell, G. (1998). Treatment completion and therapeutic change among children referred for outpatient therapy. Professional Psychology: Research and Practice, 29, 332-340.

Kim, H. (2013). Statistical notes for clinical researchers: Assessing normal distributions using skewness and kurtosis. Restorative Dentistry \& Endodontics, 38, 52-54.

Kolko, D. J., Herschell, A. D., \& Baumann, B. L. (2006). Treatment Implementation Feedback Form. Unpublished Manuscript. Pittsburgh, PA: University of Pittsburgh School of Medicine.

Kroenke, K., Spitzer, R. L., \& Williams, J. B. W. (2001). The PHQ-9: Validity of a brief depression severity measure. Journal of General Internal Medicine, 16, 606-613.

*Lai, K. Y. C., Pang, A. H. T., Wong, C. K., Lum, F., \& Lo, M. K. (1998). Characteristic of dropouts from a child psychiatry clinic in Hong Kong. Social Psychiatry and Psychiatric Epidemiology, 33, 45-48.

Lackner, J. M., Gudleski, G. D., Keefer, L., Krasner, S. S., Powell, C. \& Katz, L. A. (2010). Rapid response to cognitive behavior therapy predicts treatment outcome in patients with Irritable Bowel Syndrome. Clinical Gastroenterology and Hepatology, 8, 426-432.

Lambert, M. (2007). Presidential address: What we have learned from a decade of research aimed at improving psychotherapy outcome in routine care. Psychotherapy Research, 17, 1-14. 
Lanier, P., Kohl, P. L., Benz, J., Swinger, D., Moussette, P., \& Drake, B. (2011). Parent-Child Interaction Therapy in a community setting: Examining outcomes, attrition, and treatment setting. Research on Social Work Practice, 1, 689-698.

Linke, S. E., Gallo, L. C., \& Norman, G. J. (2011). Attrition and adherence rates of sustained vs. intermittent exercise interventions. Annals of Behavioral Medicine, 42, 197-209.

*Lock, J., Courturier, J., Bryson, S., \& Agras, S. (2006). Predictors of dropout and remission in family therapy for adolescent anorexia nervosa in a randomized clinical trail. International Journal of Eating Disorders, 39, 639-647.

Lorion, R. P. (1974). Patient and therapist variables in the treatment of low-income patients. Psychological Bulletin, 81, 344-354.

*Luk, E. S. L., Staiger, P. K., Mathai, J., Wong, L., Birleson, P., \& Adler, R. (2001). Children with persistent conduct problems who dropout of treatment. European Child \& Adolescent Psychiatry, 10, 28-36.

Lyon, A. R., \& Budd, K. S. (2010). A community mental health implementation of Parent-Child Interaction Therapy (PCIT). Journal of Child and Family Studies, 19, 654-668.

Lyon, A. R., Gershenson, R. A., Farahman, F. K., Thaxter, P. J., Behling, S., \& Budd, K. S. (2009). Effectiveness of teacher-child interaction training (TCIT) in a preschool setting. Behavior Modification, 33, 855-884.

Masse, J. J., McNeil, C. B., Wagner, S., \& Quetsch, L. B. (2016). Examining the efficacy of parent-child interaction therapy with children on the autism spectrum. Journal of Child and Family Studies, 25, 2508-2525.

*McCabe, K. M. (2002). Factors that predict premature termination among Mexican-American children in outpatient psychotherapy. Journal of Child and Family Studies, 11, 347-359. 
McDiarmid, M. D., \& Bagner, D. M. (2005). Parent child interaction therapy for children with disruptive behavior and developmental disabilities. Education \& Treatment of Children, $28,130-141$.

McNeil, C. B., \& Hembree-Kigin, T. L. (2010). Parent-Child Interaction Therapy (2 ${ }^{\text {nd }}$ ed.), New York: Springer.

Meadows, S. O., McLanahn, S. S., \& Brooks-Gunn, J. (2007). Parental depression and anxiety and early childhood behavior problems across family types. Journal of Marriage and Family, 69, 1162-1177.

Merikangas, K. R., Nakamura, E. F., \& Kessler, R. C. (2009). Epidemiology of mental disorders in children and adolescents. Dialogues in Clinical Neuroscience, 11, 7-20.

Miller, W., \& Rollnick, S. (1991). Motivational interviewing: Preparing people to change addictive behaviors. New York: Guilford Press.

*Miller, L. M., Southam-Gerow, M. A., \& Allin Jr., R. B. (2008). Who stays in treatment? Child and family predictors of youth client retention in a public mental health agency. Child Youth Care Forum, 37, 153-170.

National Research Council and Institute of Medicine. (2009). Preventing mental, emotional, and behavioral disorders among young people: Progress and possibilities. Committee on Prevention of Mental Disorders and Substance Abuse Among Children, Youth and Young Adults: Research Advances and Promising Interventions. Mary Ellen O’Connell, Thomas Boat, and Kenneth E. Warner (eds.). Board on Children, Youth, and Families, Division of Behavioral and Social Sciences and Education. Washington, DC: The National Academies Press. 
Niec, L. N., Hemme, J. M., \& Yopp, J. M. (2004). Parent-child interaction therapy: The rewards and challenges of a group format. Cognitive and Behavioral Practice, 12, 113-125.

Nixon, R. D. V., Sweeney, L., Erickson, D. B., \& Touyz, S. W. (2003). Parent-child interaction therapy: A comparison of standard and abbreviated treatments for oppositional defiant preschoolers. Journal of Consulting and Clinical Psychology, 71, 251-260.

Nixon, R. D. V., Sweeney, L., Erickson, D. B., \& Touyz, S. W. (2004). Follow-up of standard and abbreviated treatments of oppositional preschoolers. Journal of Abnormal Child Psychology, 32, 263-271.

*Nock, M. K., \& Kazdin, A. E. (2001). Parent expectancies for child therapy: Assessment and relation to participation in treatment. Journal of Child and Family Studies, 10, 155-180.

Nock, M. K., Kazdin, A. E., Hiripi, E., \& Kessler, R. C. (2007). Lifetime prevalence, correlates, and persistence of oppositional defiant disorder: Results from the National Comorbidity Survey Replication. Journal of Child Psychology and Psychiatry, 48, 703-713.

Oakes, J. M., \& Rossi, P. H. (2003). The measurement of SES in health research: Current practice and steps toward a new approach. Social Science \& Medicine, 56, 769-784.

*Pereira, T., Lock, J., \& Oggins, J. (2006). Role of therapeutic alliance in family therapy for adolescent anorexia nervosa. International Journal of Eating Disorders, 39, 677-684.

*Peters, S., Calam, R., \& Harrington, R. (2005). Maternal attributions and expressed emotion as predictors of attendance at parent management training. Journal of Child Psychology and Psychiatry, 46, 436-448.

Pincus, D. B., Eyberg, S. M., \& Choate, M. L. (2005). Adapting parent-child interaction therapy for young children with separation anxiety disorder. Education \& Treatment of Children, 28, 163-181. 
*Prinz, R. J., \& Miller, G. E. (1994). Family-based treatment for childhood antisocial behavior: Experimental influences on dropout and engagement. Journal of Consulting and Clinical Psychology, 62, 645-650.

Quetsch, L. B. (2015). A randomized controlled trial of parent-child interaction therapy with and without incentives in a community mental health setting (Doctoral dissertation proposal).

Raudenbush, S. W., Bryk, A. S., \& Congdon, R. (2011). HLM 7.00 for Windows [Computer software]. Lincolnwood, IL: Scientific Software International, Inc.

Regan, A. M., \& Hill, C. E. (1992). Investigation of what clients and counselors do not say in brief therapy. Journal of Counseling Psychology, 39, 168-174.

Reid, J. B. (1993). Prevention of conduct disorder before and after school entry: Relating interventions to developmental findings. Development and Psychopathology, 5, 243-262.

Reis, B. F., \& Brown, L. G. (2006). Preventing therapy dropout in the real world: The clinical utility of videotape preparation and client estimate of treatment duration. Professional Psychology: Research and Practice, 37, 311-316.

*Robbins, M. S., Liddle, H. A., Turner, C. W., Dakof, G. A., Alexander, J. F., \& Kogan, S. M. (2006). Adolescent and parent therapeutic alliances as predictors of dropout in Multidimensional Family Therapy. Journal of Family Psychology, 20, 108-116.

*Robbins, M. S., Turner, C. W., Alexander, J. F., \& Perez, G. A. (2003). Alliance and dropout in family therapy for adolescents with behavior problems: Individual and systematic effects. Journal of Family Psychology, 17, 534-544.

Rollnick, S., Heather, N., \& Bell, A. (1992). Negotiating behaviour change in medical settings: The development of brief motivational interview. Journal of Mental Health, 1, 25-37. 
Shapiro, D. A., Barkham, M., Stiles, W. B., Hardy, G. E., Rees, A., Reynolds, S., \& Startup, M. (2003). Time is of the essence: A selective review of the fall and rise of brief therapy research. Psychology and Psychotherapy: Theory, Research and Practice, 76, 211-235.

Sledge, W. H., Moras, K., Hartley, D., \& Levine, M. (1990). Effect of time-limited psychotherapy on patient dropout rates. The American Journal of Psychiatry, 147, 13411347.

Stiles, W. B., Leach, C., Barkham, M., Lucock, M., Iveson, S., Shapiro, D. A., Iveson, M., \& Hardy, G. E. (2003). Early sudden gains in psychotherapy under routine clinic conditions: Practice-based evidence. Journal of Consulting and Clinical Psychology, 71, 14-21.

Swift, J. K., Callahan, J., \& Levine, J. C. (2009). Using clinically significant change to identify premature termination. Psychotherapy Theory, Research, Practice, Training, 46, 328335.

Swift, J. K., \& Greenberg, R. P. (2012). Premature discontinuation in adult psychotherapy: A meta-analysis. Journal of Consulting and Clinical Psychology, 80, 547-559.

Tang, T. Z., \& DeRubeis, R. J. (1999). Sudden gains and critical sessions in cognitive-behavioral therapy for depression. Journal of Consulting and Clinical Psychology, 67, 894-904.

Timmer, S. G., Ho, L. K. L., Urquiza, A. J., Zebell, N. M., Fernandez y Garcia, E., \& Boys, D. (2011). The effectiveness of parent-child interaction therapy with depressive mothers: The changing relationship as the agent of individual change. Child Psychiatry \& Human Development, 42, 406-423.

*Venable, W. M., \& Thompson, B. (1998). Caretaker psychological factors predicting premature termination of children’s counseling. Journal of Counseling \& Development, 76, 286293. 
*Warnick, E. M., Gonzalez, A., Weersing, V. R., Scahill, L., \& Woolston, J. (2012). Defining dropout from youth psychotherapy: How definitions shape the prevalence and predictors of attrition. Child and Adolescent Mental Health, 17, 76-85.

Weis, R., Lovejoy, M. C., \& Lundahl, B. W. (2005). Factor structure and discriminative validity of the Eyberg Child Behavior Inventory with young children. Journal of Psychopathology and Behavioral Assessment, 27, 269-278.

Werba, B. E., Eyberg, S. M., Boggs, S. R., \& Algina, J. (2006). Predicting outcome in ParentChild Interaction Therapy: Success and attrition. Behavior Modification, 30, 618-646.

Wilder, F. V., \& Barrett, J. P. (2005). The association between medication usage and dropout status among participants of an exercise study for people with osteoarthritis. Physical Therapy, 85, 142-149.

Wilson, G. T. (1999). Rapid response to cognitive behavior therapy. Clinical Psychology: Science and Practice, 6, 289-292.

Woltman, H., Feldstain, A., MacKay, J. C., \& Rocchi, M. (2012). An introduction to hierarchical linear modeling. Tutorials in Quantitative Methods for Psychology, 8, 52-69.

*Yeh, M., Eastman, K., \& Cheung, M. K. (1994). Children and adolescents in community health centers: Does the ethnicity or the language of the therapist matter? Journal of Community Psychology, 22, 153-163. 


\section{Tables}

Table 1

Demographics for Children and Parents

\begin{tabular}{|c|c|c|c|c|c|c|}
\hline & \multicolumn{3}{|c|}{ Child } & \multicolumn{3}{|c|}{ Parent } \\
\hline & \multicolumn{2}{|c|}{ Frequency } & Percent & Freq & ency & Percent \\
\hline \multicolumn{7}{|l|}{ Gender } \\
\hline Male & \multicolumn{2}{|c|}{79} & $66.39 \%$ & \multicolumn{2}{|c|}{8} & $6.72 \%$ \\
\hline Female & \multicolumn{2}{|c|}{40} & $33.61 \%$ & \multicolumn{2}{|c|}{111} & $93.28 \%$ \\
\hline Race & & & & \multicolumn{2}{|c|}{119} & \\
\hline Caucasian & \multicolumn{2}{|c|}{94} & $70.68 \%$ & \multicolumn{2}{|c|}{93} & $78.15 \%$ \\
\hline African American & \multicolumn{2}{|c|}{33} & $24.81 \%$ & \multicolumn{2}{|c|}{22} & $18.9 \%$ \\
\hline $\begin{array}{l}\text { American Indian or } \\
\text { Alaska Native }\end{array}$ & \multicolumn{2}{|l|}{3} & $2.26 \%$ & \multicolumn{2}{|c|}{2} & $1.68 \%$ \\
\hline Unknown/Unreported & \multicolumn{2}{|l|}{2} & $1.50 \%$ & \multicolumn{2}{|c|}{1} & $0.84 \%$ \\
\hline Asian & \multicolumn{2}{|l|}{1} & $0.75 \%$ & \multicolumn{2}{|c|}{1} & $0.84 \%$ \\
\hline $\begin{array}{c}\text { Native Hawaiian or } \\
\text { Pacific Islander }\end{array}$ & \multicolumn{3}{|l|}{0} & \multicolumn{3}{|c|}{0} \\
\hline \multicolumn{7}{|l|}{ Ethnicity } \\
\hline Hispanic/Latino & \multicolumn{2}{|c|}{15} & $11.28 \%$ & \multicolumn{2}{|c|}{7} & $5.88 \%$ \\
\hline \multicolumn{7}{|l|}{ Minority Status } \\
\hline No & \multicolumn{2}{|c|}{71} & $61.2 \%$ & \multicolumn{2}{|c|}{86} & $75.4 \%$ \\
\hline \multirow[t]{2}{*}{ Yes } & 45 & & $38.8 \%$ & & & $24.6 \%$ \\
\hline & \multicolumn{3}{|c|}{ Frequency } & \multicolumn{3}{|c|}{ Percent } \\
\hline Condition & & & & & & \\
\hline Learning Collaborative & & 55 & & & 41 & \\
\hline Cascading & & 50 & & & 37. & \\
\hline Distance Learning & & 25 & & & 21. & \\
\hline Assessment Method at Intake & & & & & & \\
\hline Online & & 70 & & & 52. & \\
\hline Mail & & 35 & & & 26. & \\
\hline Phone & & 12 & & & 9. & \\
\hline & & $\mathrm{M}$ & & & S & \\
\hline Number of Adults in Home & & 1.7 & & & 0 . & \\
\hline Number of Children in Home & & 2.1 & & & 1. & \\
\hline & & Chi & & & $\mathrm{Pal}$ & \\
\hline & M & SD & Range & M & SD & Range \\
\hline Age & 5.35 & 1.66 & $2.02-9.84$ & 32.82 & 9.02 & $20.75-81.89$ \\
\hline
\end{tabular}


Table 2

Demographics for Children

\begin{tabular}{|c|c|c|}
\hline & Mean & SD \\
\hline \multicolumn{3}{|l|}{ ECBI } \\
\hline Intensity Raw Score & 155.73 & 39.60 \\
\hline \multirow[t]{2}{*}{ Problem Raw Score } & 22.01 & 7.16 \\
\hline & Frequency & Percent \\
\hline \multicolumn{3}{|l|}{ Referral Source } \\
\hline Behavioral/MH Provider & 76 & $65.0 \%$ \\
\hline Self & 20 & $17.1 \%$ \\
\hline Head Start/Birth to 3 & 9 & $7.7 \%$ \\
\hline Physical Health Provider & 7 & $6.0 \%$ \\
\hline Child Welfare & 5 & $4.3 \%$ \\
\hline School or Preschool & 5 & $4.3 \%$ \\
\hline Court/Legal System & 1 & $0.9 \%$ \\
\hline Other & 10 & $8.5 \%$ \\
\hline \multicolumn{3}{|l|}{ In School? } \\
\hline Yes & 98 & $84.5 \%$ \\
\hline No & 18 & $15.5 \%$ \\
\hline \multicolumn{3}{|l|}{ Grade Level } \\
\hline Preschool & 46 & $46.5 \%$ \\
\hline Kindergarten & 25 & $25.3 \%$ \\
\hline $1^{\text {st }}$ Grade & 17 & $17.2 \%$ \\
\hline $2^{\text {nd }}$ Grade & 9 & $9.1 \%$ \\
\hline $3^{\text {rd }}$ Grade & 2 & $2.0 \%$ \\
\hline \multicolumn{3}{|l|}{ Type of School } \\
\hline Regular Public & 72 & $72.7 \%$ \\
\hline Regular Private/Parochial & 8 & $8.1 \%$ \\
\hline Approved Private & 3 & $3.0 \%$ \\
\hline Charter School & 5 & $5.1 \%$ \\
\hline Cyber School & 1 & $1.0 \%$ \\
\hline Other & 10 & $10.1 \%$ \\
\hline \multicolumn{3}{|l|}{ Behavioral/MH Diagnosis } \\
\hline Yes & 75 & $66.4 \%$ \\
\hline No & 38 & $33.6 \%$ \\
\hline
\end{tabular}




\begin{tabular}{lcc} 
Diagnosis & & \\
ADHD & 61 & $54.0 \%$ \\
ODD & 33 & $29.2 \%$ \\
Developmental Delay & 22 & $19.5 \%$ \\
DBD-NOS & 21 & $18.6 \%$ \\
Adjustment Disorder & 10 & $8.8 \%$ \\
Learning Disorder & 9 & $8.0 \%$ \\
Anxiety Related to & 8 & $7.1 \%$ \\
Trauma & & \\
Anxiety Not Related to & 6 & $5.3 \%$ \\
Trauma & & \\
Autism & 6 & $5.3 \%$ \\
Reactive Attachment & 3 & $2.7 \%$ \\
CD & 2 & $1.8 \%$ \\
Depression & 2 & $1.8 \%$ \\
Intellectual Disability & 1 & $0.9 \%$ \\
Other & 5 & $4.4 \%$ \\
Medications for Behavioral/MH & & \\
Difficulties & & \\
Yes & 78 & $68.4 \%$ \\
No & 36 & $31.6 \%$ \\
\hline
\end{tabular}


Table 3

Demographics for Parents

\begin{tabular}{|c|c|c|}
\hline & Frequency & Percent \\
\hline \multicolumn{3}{|l|}{ Relationship to Child } \\
\hline Biological Mother & 119 & $88.8 \%$ \\
\hline Biological Father & 4 & $3.0 \%$ \\
\hline Adoptive Mother & 2 & $1.5 \%$ \\
\hline Adoptive Father & 1 & $0.7 \%$ \\
\hline Stepmother & 1 & $0.7 \%$ \\
\hline Stepfather & 1 & $0.7 \%$ \\
\hline Grandmother & 3 & $2.2 \%$ \\
\hline Grandfather & 2 & $1.5 \%$ \\
\hline Aunt & 1 & $0.7 \%$ \\
\hline Other & 1 & $0.7 \%$ \\
\hline \multicolumn{3}{|l|}{ Education } \\
\hline$<7^{\text {th }}$ grade & 4 & $3.6 \%$ \\
\hline Junior High School & 2 & $1.8 \%$ \\
\hline Some High School & 11 & $9.8 \%$ \\
\hline High School Graduate/GED & 44 & $39.3 \%$ \\
\hline Some College & 18 & $16.1 \%$ \\
\hline Associates Degree & 11 & $9.8 \%$ \\
\hline Standard College Degree & 7 & $6.3 \%$ \\
\hline Graduate/Professional Training & 15 & $13.4 \%$ \\
\hline \multicolumn{3}{|l|}{ Employment Status } \\
\hline Full-Time & 49 & $46.7 \%$ \\
\hline Part-Time & 19 & $18.1 \%$ \\
\hline Unemployed & 36 & $34.3 \%$ \\
\hline Retired & 1 & $1.0 \%$ \\
\hline \multicolumn{3}{|l|}{ Marital Status } \\
\hline Married & 34 & $30.9 \%$ \\
\hline Single & 56 & $50.9 \%$ \\
\hline Divorced & 14 & $12.7 \%$ \\
\hline \multirow[t]{2}{*}{ Separated } & 6 & $5.5 \%$ \\
\hline & Mean & $\mathrm{SD}$ \\
\hline $\begin{array}{l}\text { Biological Mother's Age } \\
\text { when child was born }\end{array}$ & 25.77 & 5.96 \\
\hline
\end{tabular}


Table 4

Demographics for Therapists

\begin{tabular}{|c|c|c|}
\hline & Frequency & Percent \\
\hline \multicolumn{3}{|l|}{ Gender } \\
\hline Female & 27 & $87.1 \%$ \\
\hline Male & 4 & $12.9 \%$ \\
\hline \multicolumn{3}{|l|}{ Race } \\
\hline Caucasian & 31 & $100.0 \%$ \\
\hline African American & 0 & $0.0 \%$ \\
\hline Asian & 0 & $0.0 \%$ \\
\hline Native American/Alaska Native & 0 & $0.0 \%$ \\
\hline Native Hawaiian/Pacific Islander & 0 & $0.0 \%$ \\
\hline Unknown/Not Reported & 0 & $0.0 \%$ \\
\hline \multicolumn{3}{|l|}{ Ethnicity } \\
\hline Hispanic/Latino & 1 & $3.2 \%$ \\
\hline Not Hispanic/Latino & 30 & $96.8 \%$ \\
\hline \multicolumn{3}{|l|}{ Minority Status } \\
\hline Yes & 1 & $3.2 \%$ \\
\hline No & 30 & $96.8 \%$ \\
\hline \multicolumn{3}{|l|}{ Education } \\
\hline Masters & 30 & $96.8 \%$ \\
\hline Doctoral & 1 & $3.2 \%$ \\
\hline \multicolumn{3}{|l|}{ Type Degree } \\
\hline Psychology & 12 & $38.7 \%$ \\
\hline Social Work & 10 & $32.3 \%$ \\
\hline Other & 8 & $25.8 \%$ \\
\hline Education & 1 & $3.2 \%$ \\
\hline \multicolumn{3}{|l|}{ Training Condition } \\
\hline Cascading & 15 & $48.4 \%$ \\
\hline Learning Collaborative & 9 & $29.0 \%$ \\
\hline Distance Learning & 7 & $22.6 \%$ \\
\hline \multicolumn{3}{|l|}{ Professionally Licensed } \\
\hline Yes & 14 & $45.2 \%$ \\
\hline No & 17 & $54.8 \%$ \\
\hline \multicolumn{3}{|l|}{ Part or Full Time } \\
\hline Part & 8 & $25.8 \%$ \\
\hline Full & 23 & $74.2 \%$ \\
\hline \multicolumn{3}{|l|}{ Assessment Method } \\
\hline Online & 27 & $87.1 \%$ \\
\hline Mail & 4 & $12.9 \%$ \\
\hline
\end{tabular}




\begin{tabular}{lcc}
\hline & $\mathrm{M}$ & $\mathrm{SD}$ \\
\hline Age & 36.85 years old & 10.62 \\
Years Experience & 10.84 years & 9.74 \\
Years Worked at Agency & 4.23 years & 5.19 \\
Caseload & 31.03 cases & 28.70 \\
Annual Salary (Full Time) & $\$ 43,062.50$ & $10,823.36$ \\
Hourly Rate (Part Time) & $\$ 24.88$ & 7.47 \\
Number EBP Used in Past Year & 12.48 & 5.60 \\
\% of Caseload Diagnosed & $49.48 \%$ & 26.17 \\
\multicolumn{1}{c}{ w/ Externalizing Disorder } & & \\
\hline
\end{tabular}


Table 5

Reasons for Variable Inclusion and Exclusion

\begin{tabular}{|c|c|c|c|}
\hline Variable & Source & Included? & If No, Why Not? \\
\hline \multicolumn{4}{|l|}{ Child Variables } \\
\hline Gender & Meta-analysis & Yes & \\
\hline Minority status & Meta-analysis & Yes & \\
\hline IQ & Meta-analysis & No & Not measured \\
\hline Academic functioning & Meta-analysis & No & $\begin{array}{l}\text { Measure had low construct } \\
\text { validity }\end{array}$ \\
\hline Number of diagnoses & Meta-analysis & No & Skewed \\
\hline Externalizing diagnosis & Meta-analysis & No & $\begin{array}{l}\text { Correlated with more } \\
\text { externalizing problems }\end{array}$ \\
\hline $\begin{array}{l}\text { Adjustment disorder } \\
\text { diagnosis }\end{array}$ & Meta-analysis & No & Skewed \\
\hline $\begin{array}{l}\text { Contact with deviant } \\
\text { peers }\end{array}$ & Meta-analysis & No & Not measured \\
\hline $\begin{array}{l}\text { Referral source } \\
\text { (Self-referred) }\end{array}$ & $\begin{array}{l}\text { Meta-analysis } \\
+1 \text { PCIT study }\end{array}$ & No & Skewed \\
\hline Psychotropic meds & Meta-analysis & No & Skewed \\
\hline Total problems & Meta-analysis & No & Not measured \\
\hline Social functioning & Meta-analysis & No & $\begin{array}{l}\text { Correlated with more } \\
\text { externalizing problems }\end{array}$ \\
\hline $\begin{array}{l}\text { More externalizing } \\
\text { problems (p \& t) }\end{array}$ & Meta-analysis & Yes & \\
\hline $\begin{array}{c}\text { More externalizing } \\
\text { problems (s) }\end{array}$ & Meta-analysis & No & Not measured \\
\hline \multicolumn{4}{|l|}{ Parent/Family Variables } \\
\hline Lower SES & $\begin{array}{l}\text { Meta-analysis } \\
+2 \text { PCIT studies }\end{array}$ & Yes & \\
\hline Younger mother & Meta-analysis & No & Skewed \\
\hline $\begin{array}{l}\text { Single parent } \\
\text { household }\end{array}$ & Meta-analysis & No & $\begin{array}{l}\text { Skewed } \\
\text { Measured by parent-child ratio }\end{array}$ \\
\hline $\begin{array}{l}\text { Non-biological head } \\
\text { of household }\end{array}$ & Meta-analysis & No & Skewed \\
\hline Homeless & Meta-analysis & No & Not measured \\
\hline Greater \# of siblings & Meta-analysis & No & Measured by parent-child ratio \\
\hline Total problems & Meta-analysis & No & Not measured \\
\hline $\begin{array}{l}\text { More internalizing } \\
\text { problems }\end{array}$ & $\begin{array}{l}\text { Meta-analysis } \\
+2 \text { PCIT studies }\end{array}$ & Yes & \\
\hline $\begin{array}{l}\text { More externalizing } \\
\text { problems }\end{array}$ & Meta-analysis & No & Not measured \\
\hline More negative life & Meta-analysis & No & Not measured \\
\hline
\end{tabular}




\begin{tabular}{|c|c|c|c|}
\hline events & & & \\
\hline $\begin{array}{l}\text { Poorer parenting } \\
\text { (parenting practice) }\end{array}$ & $\begin{array}{l}\text { Meta-analysis } \\
+1 \text { PCIT study }\end{array}$ & No & Skewed \\
\hline $\begin{array}{l}\text { No knowledge of } \\
\text { child's diagnosis }\end{array}$ & Meta-analysis & No & Not measured \\
\hline $\begin{array}{l}\text { Low confidence of } \\
\text { doing well in tx }\end{array}$ & Meta-analysis & No & Not measured \\
\hline Parent-to-child ratio & Committee & Yes & \\
\hline \multicolumn{4}{|l|}{$\begin{array}{l}\text { Tx or Therapist Variables/ } \\
\text { Barriers to Tx }\end{array}$} \\
\hline No ethnic match & Meta-analysis & No & Skewed \\
\hline No gender match & Meta-analysis & No & Skewed \\
\hline $\begin{array}{l}\text { More cancellations } \\
\text { or no-shows }\end{array}$ & Meta-analysis & No & Qualitative info included \\
\hline More often late & Meta-analysis & No & Qualitative info included \\
\hline $\begin{array}{l}\text { Tx beginning and/or } \\
\text { progressing too } \\
\text { slow (Wait time) }\end{array}$ & $\begin{array}{l}1 \text { meta-analysis } \\
+1 \text { PCIT study }\end{array}$ & Yes & \\
\hline BTPS total barriers (p) & $\begin{array}{l}+1 \text { PCIT study } \\
\text { Meta-analysis }\end{array}$ & No & Skewed \\
\hline BTPS total barriers (th) & Meta-analysis & No & Not measured \\
\hline $\begin{array}{l}\text { BTPS more stressors } \\
\text { obstacles (p) }\end{array}$ & $\begin{array}{l}\text { Meta-analysis } \\
+1 \text { PCIT study }\end{array}$ & Yes & \\
\hline $\begin{array}{l}\text { BTPS more stressors } \\
\text { obstacles (th) }\end{array}$ & Meta-analysis & No & Not measured \\
\hline $\begin{array}{l}\text { BTPS more tx } \\
\text { demands }(p)\end{array}$ & Meta-analysis & No & Skewed \\
\hline $\begin{array}{l}\text { BTPS more tx } \\
\text { demands (th) }\end{array}$ & Meta-analysis & No & Not measured \\
\hline $\begin{array}{l}\text { BTPS lower perceived } \\
\text { relevance }(p)\end{array}$ & Meta-analysis & No & Skewed \\
\hline $\begin{array}{l}\text { BTPS lower perceived } \\
\text { relevance (th) }\end{array}$ & Meta-analysis & No & Not measured \\
\hline $\begin{array}{l}\text { BTPS lower thera. } \\
\text { relationship (p) }\end{array}$ & $\begin{array}{l}\text { Meta-analysis } \\
+1 \text { PCIT study }\end{array}$ & No & Skewed \\
\hline $\begin{array}{l}\text { BTPS lower thera. } \\
\text { relationship (th) }\end{array}$ & Meta-analysis & No & Not measured \\
\hline $\begin{array}{l}\text { Therapist: care, } \\
\text { concern, comm., } \\
\text { facilitative, } \\
\text { charisma, support. }\end{array}$ & Meta-analysis & No & Not measured \\
\hline $\begin{array}{l}\text { Therapist: directive, } \\
\text { cont., confronting }\end{array}$ & Meta-analysis & No & Not measured \\
\hline Focus of therapy (cog., & Meta-analysis & Yes & \\
\hline
\end{tabular}




\begin{tabular}{|c|c|c|c|}
\hline $\begin{array}{l}\text { behav., interpret.) } \\
\text { and tx modality - } \\
\text { (Satisfaction w/ tx) }\end{array}$ & \multicolumn{3}{|c|}{+2 PCIT studies } \\
\hline $\begin{array}{l}\text { Therapy: less well } \\
\text { organized }\end{array}$ & Meta-analysis & No & Not measured \\
\hline $\begin{array}{l}\text { Expecting the child to } \\
\text { recover quickly }\end{array}$ & Meta-analysis & No & Not measured \\
\hline $\begin{array}{l}\text { Unbalanced alliance } \\
\text { parent/child }\end{array}$ & Meta-analysis & No & Not measured \\
\hline $\begin{array}{l}\text { Higher unbalanced } \\
\text { alliance father-child }\end{array}$ & Meta-analysis & No & Not measured \\
\hline $\begin{array}{l}\text { Higher unbalanced } \\
\text { alliance mother-chd }\end{array}$ & Meta-analysis & No & Not measured \\
\hline Child alliance & Meta-analysis & No & Not measured \\
\hline Parent alliance & Meta-analysis & No & Not measured \\
\hline $\begin{array}{l}\text { Reduction in } \\
\text { adolescent alliance }\end{array}$ & Meta-analysis & No & Not measured \\
\hline $\begin{array}{l}\text { Reduction in parent } \\
\text { alliance }\end{array}$ & Meta-analysis & No & Not measured \\
\hline $\begin{array}{l}\text { Transportation } \\
\text { problems }\end{array}$ & Committee & No & Skewed \\
\hline Childcare problems & Committee & No & $\begin{array}{l}\text { Measured qualitatively } \\
\text { Qualitative info included }\end{array}$ \\
\hline Bad weather/season & Committee & No & $\begin{array}{l}\text { Measured qualitatively } \\
\text { Qualitative info included }\end{array}$ \\
\hline Child or sibling ill & Committee & No & $\begin{array}{l}\text { Measured qualitatively } \\
\text { Qualitative info included }\end{array}$ \\
\hline Pregnant mother & Committee & No & $\begin{array}{l}\text { Measured qualitatively } \\
\text { Qualitative info included }\end{array}$ \\
\hline Family moved & Committee & No & Qualitative info included \\
\hline Parent hostility & Committee & No & Qualitative info included \\
\hline Theoretical orientation & Committee & No & Not measured \\
\hline $\begin{array}{l}\text { Therapist satisfaction } \\
\text { with tx }\end{array}$ & Committee & Yes & \\
\hline
\end{tabular}


Table 6

Means and Standard Deviations for Continuous Variables

\begin{tabular}{|c|c|c|c|}
\hline Variable & M & SD & Range (Possible range) \\
\hline \multicolumn{4}{|l|}{ Child Variables } \\
\hline Externalizing Behavior & 155.73 & 39.60 & $52-243(36-252)$ \\
\hline \multicolumn{4}{|l|}{ Parent Variables } \\
\hline Depression & 8.60 & 6.60 & $0-24(0-36)$ \\
\hline Satisfaction with PCIT & 39.62 & 7.57 & $21-50(0-50)$ \\
\hline \multicolumn{4}{|l|}{ Parent-to-Child Ratio* } \\
\hline \multicolumn{4}{|l|}{ Wait for PCIT* } \\
\hline \multicolumn{4}{|l|}{ Competing Activities/Life Stressors* } \\
\hline \multicolumn{4}{|l|}{ Therapist Variables } \\
\hline Satisfaction with PCIT & 4.51 & 0.60 & $3-5(1-5)$ \\
\hline Note. ${ }^{*}$ Variables were Recoded into Cate & Variables & & \\
\hline
\end{tabular}


Table 7

Frequency and Percent for Categorical Variables

\begin{tabular}{|c|c|c|}
\hline Variable & Frequency & Percent \\
\hline \multicolumn{3}{|l|}{ Attrition } \\
\hline Premature terminators & 98 & $73.13 \%$ \\
\hline Completers & 36 & $26.87 \%$ \\
\hline \multicolumn{3}{|l|}{ Gender } \\
\hline Male & 79 & $66.40 \%$ \\
\hline Female & 40 & $33.60 \%$ \\
\hline \multicolumn{3}{|l|}{ Minority Status } \\
\hline Yes & 45 & $38.80 \%$ \\
\hline No & 71 & $61.20 \%$ \\
\hline \multicolumn{3}{|l|}{ Income } \\
\hline$\leq \$ 14,999$ & 58 & $53.7 \%$ \\
\hline$\$ 15,000-29,999$ & 22 & $20.4 \%$ \\
\hline$\$ 30,000-74,999$ & 13 & $12.0 \%$ \\
\hline$\geq \$ 75,000 X$ & 15 & $13.9 \%$ \\
\hline \multicolumn{3}{|l|}{ Parent-to-Child Ratio } \\
\hline$<1 / 2$ & 19 & $17.0 \%$ \\
\hline $1 / 2<1 / 1$ & 29 & $25.9 \%$ \\
\hline $1 / 1$ & 38 & $33.9 \%$ \\
\hline$>1 / 1$ & 26 & $23.2 \%$ \\
\hline \multicolumn{3}{|l|}{ Wait for PCIT } \\
\hline$>1$ week & 13 & $11.0 \%$ \\
\hline 1 week & 37 & $31.4 \%$ \\
\hline 1-2 weeks & 27 & $22.9 \%$ \\
\hline 2-3 weeks & 17 & $14.4 \%$ \\
\hline 3-4 weeks & 10 & $8.5 \%$ \\
\hline $1-1.5$ months & 9 & $7.6 \%$ \\
\hline$>1.5$ months & 5 & $4.2 \%$ \\
\hline \multicolumn{3}{|l|}{ Competing Activities/ Life } \\
\hline \multicolumn{3}{|l|}{ Stressors } \\
\hline $0-1$ & 11 & $12.6 \%$ \\
\hline $2-4$ & 11 & $12.6 \%$ \\
\hline $5-6$ & 11 & $12.6 \%$ \\
\hline $7-9$ & 14 & $16.1 \%$ \\
\hline $10-11$ & 8 & $9.2 \%$ \\
\hline $12-16$ & 11 & $12.6 \%$ \\
\hline $17-22$ & 10 & $11.5 \%$ \\
\hline $23-29$ & 7 & $8.0 \%$ \\
\hline $30+$ & 4 & $4.6 \%$ \\
\hline
\end{tabular}


Table 8

Intraclass Correlations Between Predictor Variables

\begin{tabular}{|c|c|c|c|c|c|c|c|c|c|c|}
\hline Measure & 1 & 2 & 3 & 4 & 5 & 6 & 7 & 8 & 9 & 10 \\
\hline 1. Gender & -- & & & & & & & & & \\
\hline 2. Minority Status & -0.11 & -- & & & & & & & & \\
\hline 3. Externalizing Behavior & 0.07 & 0.06 & -- & & & & & & & \\
\hline 4. Income & -0.11 & -0.16 & -0.05 & -- & & & & & & \\
\hline 5. Parent-to-Child Ratio & 0.01 & $0.24^{*}$ & $0.23^{*}$ & -0.19 & -- & & & & & \\
\hline 6. Parent Depression & 0.05 & 0.004 & $0.31 * *$ & -0.05 & 0.07 & -- & & & & \\
\hline 7. Wait for PCIT & 0.06 & 0.10 & -0.06 & -0.05 & 0.004 & -0.15 & -- & & & \\
\hline 8. Competing Activities/ Stressors & -0.04 & -0.07 & $0.48 * *$ & 0.06 & $0.25 *$ & $0.31 * *$ & -0.04 & -- & & \\
\hline 9. Parent Satisfaction & -0.12 & -0.07 & $-0.49 * *$ & 0.11 & $-0.25 *$ & -0.05 & -0.09 & $-0.54 * *$ & -- & \\
\hline 10. Therapist Satisfaction & -0.07 & 0.08 & $-0.22 *$ & -0.08 & -0.10 & -0.18 & -0.03 & -0.07 & 0.10 & -- \\
\hline
\end{tabular}

$* \mathrm{p}<.05, * * \mathrm{p}<.01$ 
Table 9

Total CDI Coach Sessions Attended By Families who Dropped Out

\begin{tabular}{lc|lc}
\hline \# CDI Coach & \# (\%) of Families & \# CDI Coach & \# (\%) of Families \\
\hline 1 & $11(15.07)$ & 9 & $3(4.11)$ \\
2 & $12(16.44)$ & 10 & $3(4.11)$ \\
3 & $9(12.33)$ & 11 & $2(2.74)$ \\
4 & $7(9.59)$ & 13 & $1(1.37)$ \\
5 & $4(5.48)$ & 14 & $1(1.37)$ \\
6 & $9(12.33)$ & 15 & $1(1.37)$ \\
7 & $3(4.11)$ & 16 & $2(2.74)$ \\
8 & $4(5.48)$ & 23 & $1(1.37)$ \\
\hline
\end{tabular}


Table 10

Number of PCIT Coach Sessions Attended

\begin{tabular}{lllll}
\hline Session & $\mathrm{N}$ & Mean & SD & Range \\
\hline CDI Coach & 133 & 5.28 & 5.21 & $0-31$ sessions \\
Graduated & 36 & 8.58 & 5.70 & $2-31$ sessions \\
Dropped out & 97 & 4.05 & 4.45 & $0-23$ sessions \\
PDI Coach & 133 & 2.66 & 4.51 & $0-29$ sessions \\
Graduated & 36 & 8.56 & 4.70 & $3-29$ sessions \\
Dropped out & 97 & 0.47 & 1.42 & $0-7$ sessions \\
\hline
\end{tabular}


Table 11

HLM of Predictors of Attrition in PCIT with Training Condition Included

\begin{tabular}{lccccccccc}
\hline & \multicolumn{1}{c}{ Training Condition } & Not Included & \multicolumn{3}{c}{ Training Condition Included } \\
\hline Variable & Coefficient & $S E$ & $t$ & $d f$ & Coefficient & $S E$ & $t$ & $d f$ \\
Gender & 0.06 & 0.33 & 0.17 & 20 & -0.24 & 0.43 & -0.55 & 18 \\
Ethnic minority & & & & & -0.16 & 0.63 & -0.25 & 18 \\
Externalizing bx & -0.01 & 0.01 & -1.09 & 20 & -0.01 & 0.01 & -1.06 & 18 \\
Family income & $0.49 * *$ & 0.17 & 2.83 & 20 & 0.35 & 0.27 & 1.33 & 18 \\
Parent-to-Child ratio & -0.37 & 0.20 & -1.85 & 18 & $-0.51^{*}$ & 0.22 & -2.29 & 18 \\
Parent depression & -0.01 & 0.03 & -0.21 & 20 & 0.01 & 0.04 & 0.14 & 18 \\
Wait for PCIT & 0.01 & 0.01 & 0.66 & 20 & $-0.02^{*}$ & 0.01 & -2.49 & 18 \\
Life stressors & $-0.52^{* *}$ & 0.15 & -3.49 & 20 & $-0.66^{* *}$ & 0.19 & -3.49 & 18 \\
Parent Satisfaction & $0.17 * *$ & 0.03 & 5.32 & 20 & $0.18^{* *}$ & 0.04 & 5.07 & 18 \\
Therapist Satisfaction & & & & & & & & & \\
\hline$*$
\end{tabular}

${ }^{*} \mathrm{p}<.05, * * \mathrm{p}<.01$

SE: Standard error 
Table 12

Negative Impacts on Overall Course and Outcome of Treatment

\begin{tabular}{lccc}
\hline Issues & N & $\begin{array}{c}\text { Number of } \\
\text { Families }\end{array}$ & Percent \\
\hline Conflict with work and family schedules/too busy & 131 & 71 & $54.2 \%$ \\
Marital discord/conflict & 132 & 36 & $27.3 \%$ \\
Other & 132 & 35 & $26.5 \%$ \\
Severity of parental mental health problems & 132 & 27 & $20.5 \%$ \\
Residential instability - moves, no phone, etc. & 132 & 24 & $18.2 \%$ \\
Conflict with an outside family member/friend & 132 & 21 & $15.9 \%$ \\
Limited parental cognitive skills & 132 & 16 & $12.1 \%$ \\
Family involvement in other treatment programs that & 132 & 16 & $12.1 \%$ \\
$\quad$ interfere/compete with PCIT services & 132 & 10 & $7.6 \%$ \\
Parent very angry or hostile & 132 & 9 & $6.8 \%$ \\
Parent out of the home & 131 & 8 & $6.1 \%$ \\
Drug/alcohol problem & 132 & 7 & $5.3 \%$ \\
Limited child cognitive skills & 132 & 5 & $3.8 \%$ \\
Child out of the home & 132 & 5 & $3.8 \%$ \\
Domestic violence & 132 & 4 & $3.0 \%$ \\
Having to “childline” a family or report suspected & & & $0.8 \%$ \\
$\quad$ abuse to child welfare & 132 & 1 & \\
Dangerous community & & & \\
\hline
\end{tabular}


Table 13

Other Negative Impacts on Overall Course and Outcome of Treatment

\begin{tabular}{lc}
\hline Other Negative Impacts & Number of Families \\
\hline Logistical barriers & \\
Parent in/preparing for/recently returning from incarceration & 4 \\
New baby & 3 \\
Limited transportation & 2 \\
No childcare & 1 \\
Mother lived far away & 1 \\
Relatives moved into home - stress & 1 \\
Treatment for caregiver/other family member & 1 \\
Behavioral problems with other children in home & 1 \\
Poor financials & 1 \\
Treatment resistance/commitment & \\
Cancellations/no shows/inconsistency & 4 \\
Difficulties with calling/scheduling & 3 \\
Unresponsive to coaching & 3 \\
Disinterest & 3 \\
PCIT not appropriate & \\
Limited speech & 3 \\
ASD diagnosis & 2 \\
No behavioral concerns & \\
"Deeper issues other than behavioral” & 1 \\
Other & 1 \\
Mother and child not bonded & \\
Parents felt other issues with child more pressing & 1 \\
\hline
\end{tabular}


Table 14

Why PCIT Services Ended

\begin{tabular}{|c|c|c|c|}
\hline Reason & $\mathrm{N}$ & $\begin{array}{l}\text { Number of } \\
\text { Families }\end{array}$ & Percent \\
\hline No-shows & 134 & 50 & $37.3 \%$ \\
\hline Disinterest in PCIT/low motivation & 134 & 43 & $32.1 \%$ \\
\hline Graduated from treatment & 134 & 37 & $27.6 \%$ \\
\hline Problems got better/clinical improvement & 133 & 35 & $26.3 \%$ \\
\hline Cancellations & 134 & 34 & $25.4 \%$ \\
\hline Other & 133 & 31 & $23.3 \%$ \\
\hline Family felt PCIT services were no longer needed & 134 & 31 & $23.1 \%$ \\
\hline Therapist felt PCIT services were no longer needed & 133 & 23 & $17.3 \%$ \\
\hline $\begin{array}{l}\text { Non-compliance with PCIT by patient and/or family during } \\
\text { sessions }\end{array}$ & 134 & 22 & $16.4 \%$ \\
\hline Schedule conflicts & 134 & 22 & $16.4 \%$ \\
\hline $\begin{array}{l}\text { Limited resources/unable to attend due to time, transportation, or } \\
\text { money }\end{array}$ & 134 & 8 & $6.0 \%$ \\
\hline Family or child moved/no longer available/missing & 134 & 8 & $6.0 \%$ \\
\hline Major crises or family emergency, including serious illness & 134 & 7 & $5.2 \%$ \\
\hline $\begin{array}{l}\text { Do not like therapy (i.e., PCIT), therapist, or other aspects of the } \\
\text { service }\end{array}$ & 133 & 5 & $3.8 \%$ \\
\hline Problem got worse/clinical deterioration & 134 & 5 & $3.7 \%$ \\
\hline Legal problems that prevent family’s participation & 134 & 3 & $2.2 \%$ \\
\hline Insurance company or policy constraints/issues & 134 & 3 & $2.2 \%$ \\
\hline Child removed from home & 134 & 1 & $0.7 \%$ \\
\hline
\end{tabular}




\section{Table 15}

Other Reasons Why PCIT Services Ended

\begin{tabular}{lc}
\hline Reason & Frequency \\
\hline Health issues with another child & 2 \\
Parent incarcerated & 2 \\
Dad heart attack & 1 \\
Domestic abuse from biological father & 1 \\
Parent reported unknown crisis & 1 \\
\hline
\end{tabular}


Table 16

Recommendations After Discharge

\begin{tabular}{lccc}
\hline Service & Number of \\
Outpatient treatment & 134 & 39 & $29.1 \%$ \\
BHRS (wraparound) & 134 & 29 & $21.6 \%$ \\
Other & 134 & 28 & $20.9 \%$ \\
Intensive case management/resource coordination (face-to-face) & 134 & 20 & $14.9 \%$ \\
Community supportive services & 134 & 10 & $7.5 \%$ \\
Family-based & 134 & 9 & $6.7 \%$ \\
Family-therapy & 134 & 5 & $3.7 \%$ \\
Partial hospitalization or day treatment & 134 & 3 & $2.2 \%$ \\
Administrative case management (not face-to-face) & 134 & 3 & $2.2 \%$ \\
Support group & 134 & 1 & $0.7 \%$ \\
Inpatient hospitalization or day treatment & 134 & 0 & $0.0 \%$ \\
Residential treatment & 134 & 0 & $0.0 \%$ \\
\hline
\end{tabular}




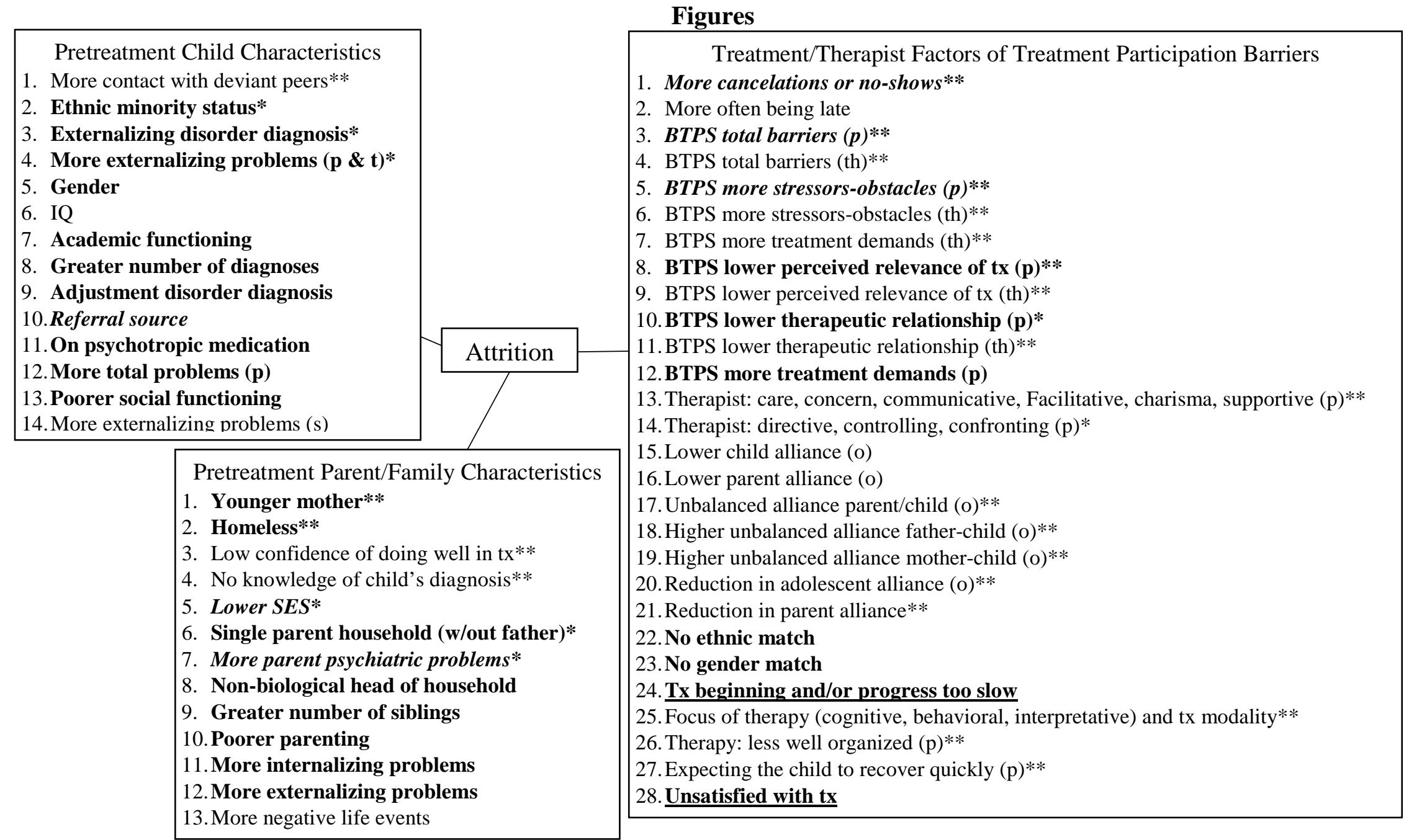

Figure 1. Chart showing significant predictors of attrition in meta-analysis and PCIT studies.

$(\mathrm{p})=$ parent; $(\mathrm{t})=$ teacher; $(\mathrm{th})=$ therapist; $(\mathrm{s})=$ self; $(\mathrm{o})=$ observer; BTPS = Barriers to Treatment Participation Scale; $\mathrm{tx}=$ treatment. *Small effect size, predictor found in at least 10 studies with a high number of total respondents

**Medium to very large effect size

Bold = measured in current study; Italicized = significant in at least one PCIT study; Underlined = found only in a PCIT study. 


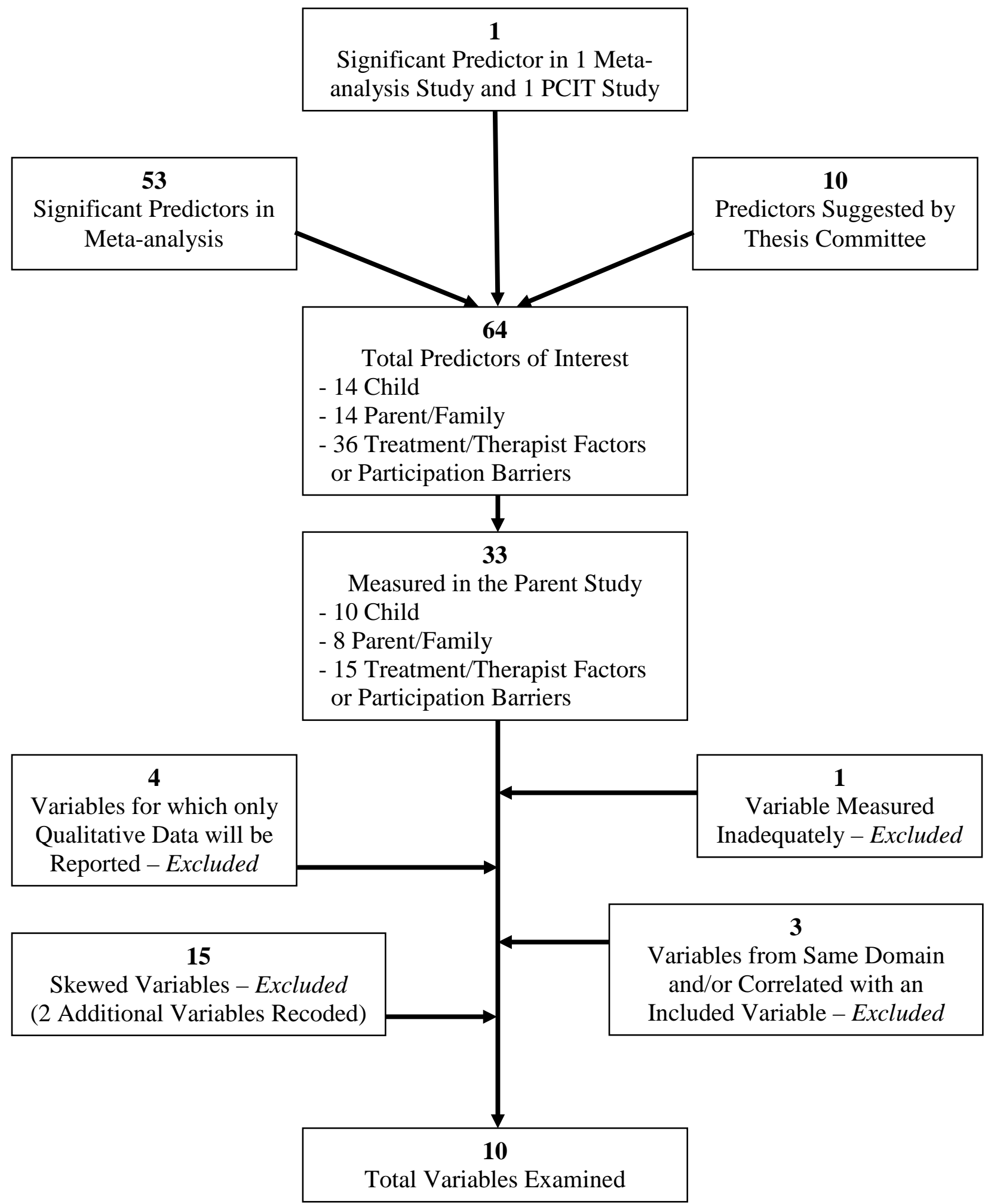

Figure 2. Flow chart showing variable choice 


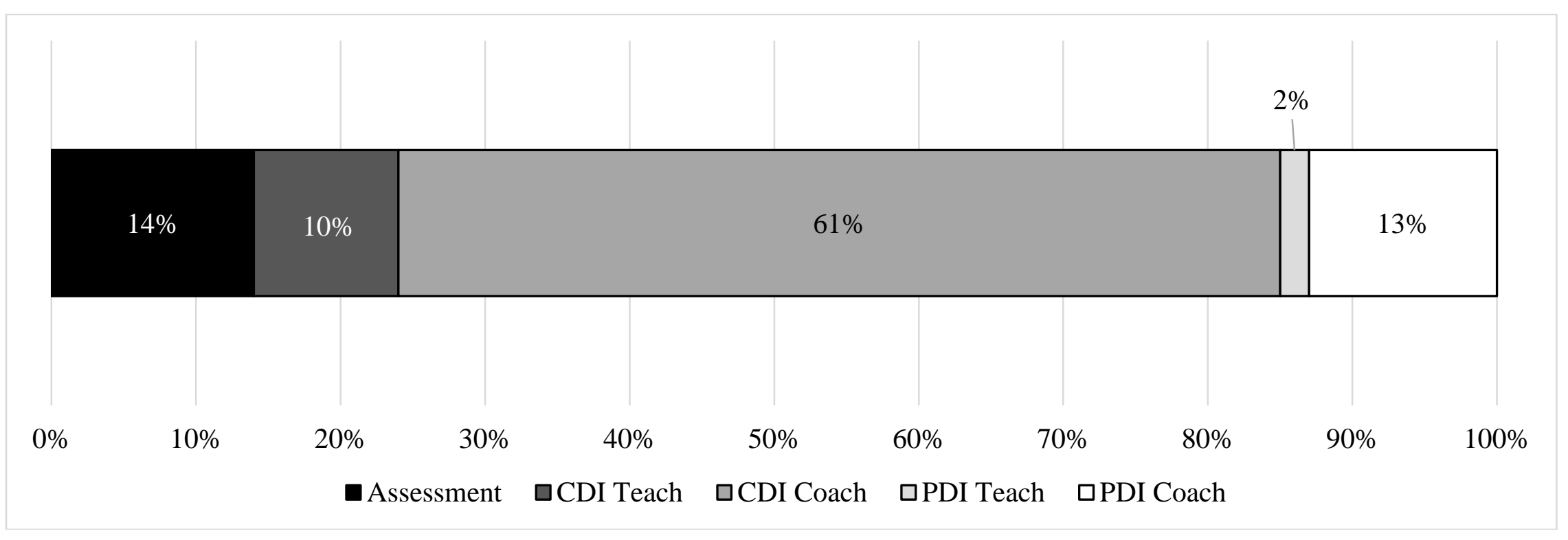

Figure 3. Timeline of when families left therapy prematurely. 


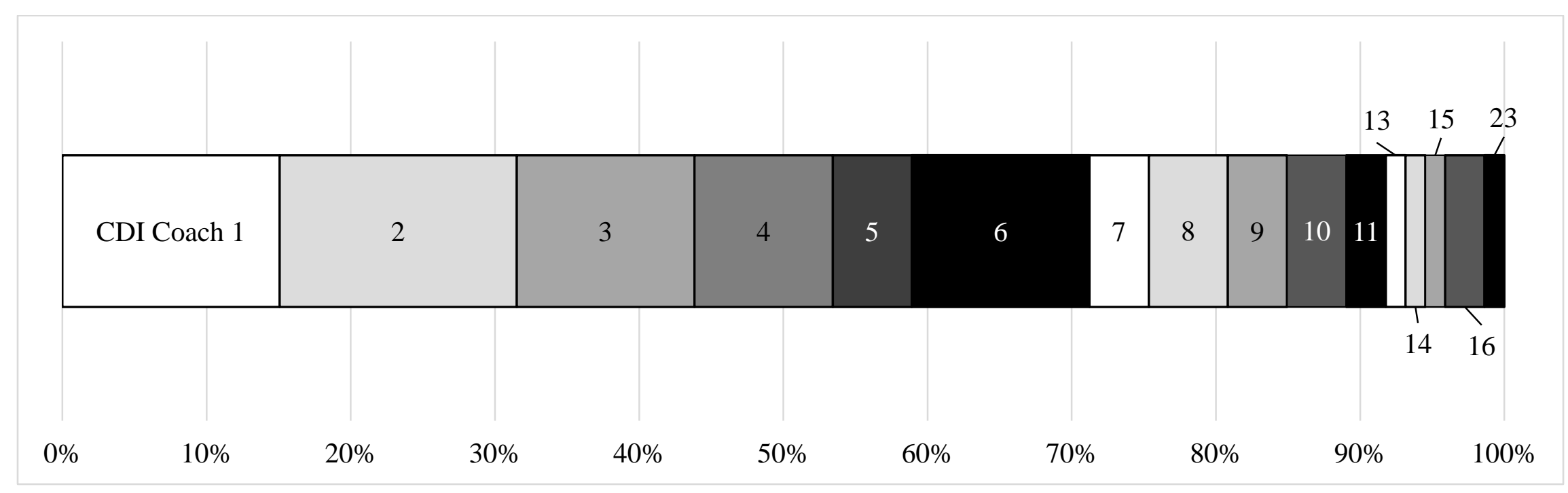

Figure 4. Number of CDI sessions attended by premature terminators before leaving therapy. 